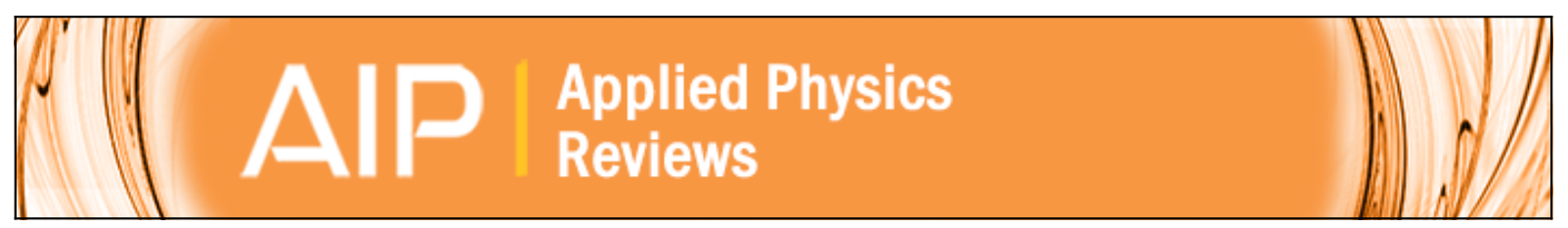

\title{
Oxygen defect processes in silicon and silicon germanium
}

A. Chroneos, E. N. Sgourou, C. A. Londos, and U. Schwingenschlögl

Citation: Applied Physics Reviews 2, 021306 (2015); doi: 10.1063/1.4922251

View online: http://dx.doi.org/10.1063/1.4922251

View Table of Contents: http://scitation.aip.org/content/aip/journal/apr2/2/2?ver=pdfcov

Published by the AIP Publishing

\section{Articles you may be interested in}

Defect engineering of the oxygen-vacancy clusters formation in electron irradiated silicon by isovalent doping: An infrared perspective

J. Appl. Phys. 112, 123517 (2012); 10.1063/1.4770488

Defect configurations of high-k cations in germanium

J. Appl. Phys. 111, 023714 (2012); 10.1063/1.3679089

Point defect engineering strategies to suppress A-center formation in silicon

Appl. Phys. Lett. 99, 241901 (2011); 10.1063/1.3666226

Interaction of A-centers with isovalent impurities in silicon

J. Appl. Phys. 107, 093518 (2010); 10.1063/1.3409888

Electronic properties of vacancy-oxygen complex in Ge crystals

Appl. Phys. Lett. 81, 1821 (2002); 10.1063/1.1504871

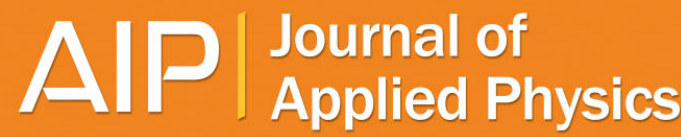

Journal of Applied Physics is pleased to announce André Anders as its new Editor-in-Chief 


\title{
Oxygen defect processes in silicon and silicon germanium
}

\author{
A. Chroneos, ${ }^{1,2, a)}$ E. N. Sgourou, ${ }^{3}$ C. A. Londos, ${ }^{3}$ and U. Schwingenschlögl ${ }^{4}$ \\ ${ }^{1}$ Faculty of Engineering and Computing, Coventry University, Priory Street, Coventry CV1 5FB, \\ United Kingdom \\ ${ }^{2}$ Department of Materials, Imperial College London, London SW7 2BP, United Kingdom \\ ${ }^{3}$ Solid State Section, Physics Department, University of Athens, Panepistimiopolis, Zografos, 15784 Athens, \\ Greece \\ ${ }^{4}$ PSE Division, KAUST, Thuwal 23955-6900, Saudi Arabia
}

(Received 28 April 2015; accepted 19 May 2015; published online 18 June 2015)

\begin{abstract}
Silicon and silicon germanium are the archetypical elemental and alloy semiconductor materials for nanoelectronic, sensor, and photovoltaic applications. The investigation of radiation induced defects involving oxygen, carbon, and intrinsic defects is important for the improvement of devices as these defects can have a deleterious impact on the properties of silicon and silicon germanium. In the present review, we mainly focus on oxygen-related defects and the impact of isovalent doping on their properties in silicon and silicon germanium. The efficacy of the isovalent doping strategies to constrain the oxygen-related defects is discussed in view of recent infrared spectroscopy and density functional theory studies. (C) 2015 AIP Publishing LLC.
\end{abstract}

[http://dx.doi.org/10.1063/1.4922251]

\section{TABLE OF CONTENTS}

I. INTRODUCTION

II. OXYGEN, CARBON, AND INTRINSIC

DEFECTS IN SI.

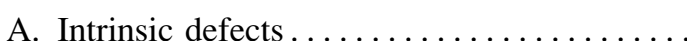

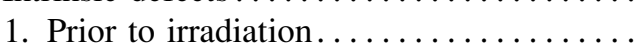

2. After irradiation ....................

3. Impact of isochronal annealing ........

B. Oxygen $\ldots \ldots \ldots \ldots \ldots \ldots \ldots \ldots \ldots \ldots$



2. The $\mathrm{VO}_{2}$ defect $\ldots \ldots \ldots \ldots \ldots \ldots \ldots$

3. The $\mathrm{V}_{\mathrm{m}} \mathrm{O}_{\mathrm{n}}$ defects $\ldots \ldots \ldots \ldots \ldots \ldots \ldots$

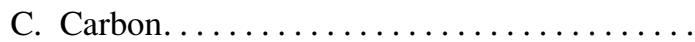

III. OXYGEN DIFFUSION PROCESSES IN SI ...

IV. POINT DEFECT ENGINEERING

\section{STRATEGIES TO RESTRAIN OXYGEN}

DIFFUSION IN SI

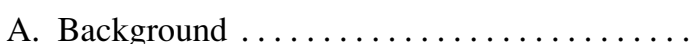

B. Doping with large isovalent atoms.......

1. Ge doping in $\mathrm{Si} \ldots \ldots \ldots \ldots \ldots \ldots$

2. Sn doping in $\mathrm{Si} \ldots \ldots \ldots \ldots \ldots \ldots$

3. $\mathrm{Pb}$ doping in $\mathrm{Si} \ldots \ldots \ldots \ldots \ldots \ldots$

V. OXYGEN RELATED DEFECTS IN SIGE.....

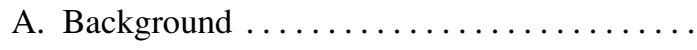

B. Impact of Ge content $\ldots \ldots \ldots \ldots \ldots \ldots$

VI. INSIGHTS FROM ADVANCED

COMPUTATIONAL TECHNIQUES

A. Background

a)Electronic mail: alexander.chroneos@imperial.ac.uk
B. A-centers revisited $\ldots \ldots \ldots \ldots \ldots \ldots \ldots$

C. Carbon related defects ............. 10

D. Insights on isovalent doping ......... 11 VII. SUMMARY AND FUTURE DIRECTIONS ... 12

\section{INTRODUCTION}

Silicon ( $\mathrm{Si}$ ) has been the dominant microelectronic material for decades aided by the advantageous properties of its native oxide $\left(\mathrm{SiO}_{2}\right)$. In the past few years, the introduction of high- $k$ gate dielectric materials has eliminated the requirement of a good quality native oxide. ${ }^{1-3}$ This has regenerated the interest to use alternative semiconductor materials such as silicon germanium $\left(\mathrm{Si}_{1-\mathrm{x}} \mathrm{Ge}_{\mathrm{x}}\right)$ and germanium $(\mathrm{Ge})$. These are appropriate candidate materials for the use in advanced nanoelectronic devices as they have a number of advantages over Si including their superior carrier mobilities, smaller band-gap, and low dopant activation temperatures. ${ }^{4-6}$ Considering $\mathrm{Si}_{1-\mathrm{x}} \mathrm{Ge}_{\mathrm{x}}$, another advantage is its compatibility to $\mathrm{Si}$-processes and therefore existing $\mathrm{Si}$ process equipment has been/and may be used or adapted for $\mathrm{Si}_{1-\mathrm{x}} \mathrm{Ge}_{\mathrm{x}}$ device fabrication.

Defects can be introduced in $\mathrm{Si}$ and $\mathrm{Si}_{1-\mathrm{x}} \mathrm{Ge}_{\mathrm{x}}$ during the Czochralski crystal growth (from the graphite and $\mathrm{SiO}_{2}$ components), device processing (e.g., implantation), during operation (for instance, by radiation in space or radiation damage in accelerators), and by contamination with impurities. Controlling defects can be important during wafer fabrication and device processing in order to prevent device degradation. $^{7-15}$

O-related defects have been investigated systematically in $\mathrm{Si}$ and to a lesser degree in $\mathrm{Ge}$ or $\mathrm{Si}_{1-\mathrm{x}} \mathrm{Ge}_{\mathrm{x}}$ for over five 
decades. This is because $\mathrm{O}$, which is introduced in the lattice mainly due to the growth or processing stages, impacts the properties of $\mathrm{Si}$ and $\mathrm{Si}_{1-\mathrm{x}} \mathrm{Ge}_{\mathrm{x}}$. Defects, such as the vacancyoxygen pair (known as the A-center), have been studied since the early seminal investigations of Watkins (refer to Ref. 16 for an overview) but there is still a need to limit their deleterious impact. For example, A-centers in Si impact the operation of Charge-Coupled Devices (CCDs) in space. In particular, they interfere with the readout process and transfer signal by one or more pixels against the direction of transfer through the device. ${ }^{17}$ This impacts the picture quality from space missions and is a unique demonstration of how atomic scale defects can constrict our understanding of extremely large objects in space. ${ }^{17}$

The understanding of defect processes in materials has been aided by the ever increasing computational power, availability of resources, and advances in computational techniques. ${ }^{18-25}$ These have allowed the fundamental understanding of the structure and electronic properties of defects and their clusters at an atomistic scale providing exciting insights. In essence, they do not provide only information complementary to experiment but can be employed in conjunction with experiment to design defect engineering strategies to limit the impact of the O-related defects.

The present review is mainly focused on the O-related defects and processes in $\mathrm{Si}$ and Ge. In the first part, we discuss $\mathrm{O}, \mathrm{C}$, intrinsic defects, and their respective clusters. Important defects, such as the A-center, are discussed extensively from both an experimental and density functional theory (DFT) perspective. This is followed by an assessment of point defect engineering strategies using oversized isovalent atoms, which aim to control the O-related defects. Finally, to conclude a brief summary and outlook for future directions is given.

\section{OXYGEN, CARBON, AND INTRINSIC DEFECTS IN Si}

\section{A. Intrinsic defects}

Vacancies $(V)$ and self-interstitials $\left(\mathrm{Si}_{\mathrm{I}}\right)$ are intrinsic point defects that have an important role in many defect processes including self- or dopant diffusion, strain release in the lattice, and radiation defects. The formation of radiation defects is the result of direct or indirect participation of intrinsic defect and various impurities or dopants in the host material. A common way to study radiation defects in a controlled and systematic manner is by irradiation with electrons, neutrons, protons, or gamma rays. In these irradiated materials, vacancies and interstitials form at non-equilibrium concentrations. ${ }^{26}$ These $V$ and self-interstitials can form pairs and/or complexes with other intrinsic defects or dopant atoms present in the lattice. Vacancies typically form divacancies $\left(V_{2}\right)$, or they are captured by $\mathrm{O}$ to form $V \mathrm{O}$ pairs. The $\mathrm{Si}_{I}$ 's can associate directly or indirectly with $\mathrm{C}$ and $\mathrm{O}$ impurities to form many complexes, including the $\mathrm{C}_{\mathrm{i}} \mathrm{O}_{\mathrm{i}}$, the $\mathrm{C}_{\mathrm{i}} \mathrm{C}_{\mathrm{s}}$, and the $\mathrm{C}_{\mathrm{i}} \mathrm{O}_{\mathrm{i}}(\mathrm{Si})_{\mathrm{I}}{ }^{15}$

\section{Prior to irradiation}

A way to investigate the temperature evolution of defects in irradiated Si is infrared spectroscopy. Previous studies reported the sequential appearance upon annealing of defects in irradiated $\mathrm{Cz}-\mathrm{Si}$ containing $\mathrm{C}$ as detected by infrared spectroscopy. ${ }^{27-29}$ Prior to irradiation, the O interstitials give rise to a number of IR bands in the spectra in the frequency range of $25-1835 \mathrm{~cm}^{-1}$ (refer to Fig. 1(a) and Ref. 30). The most important band is that being at $1106 \mathrm{~cm}^{-1}$, from which the $\mathrm{O}$ concentration of the material is calculated using a calibration coefficient of 3.14 $\times 10^{17} \mathrm{~cm}^{-2}$. The $\mathrm{C}$ substitutionals give rise to an IR band at $605 \mathrm{~cm}^{-1}$ from which the $\mathrm{C}$ concentration of the material is calculated using a calibration coefficient of $1.0 \times 10^{17} \mathrm{~cm}^{-2}$. The $\mathrm{C}$ substitutional-O interstitial pairs $\left(\mathrm{C}_{\mathrm{s}} \mathrm{O}_{\mathrm{i}}\right)$ give rise to IR bands at $585,637,684$, and $1004 \mathrm{~cm}^{-1}$. The latter band may not be seen as it is masked by the much stronger band of $\mathrm{O}_{\mathrm{i}}$ at $1006 \mathrm{~cm}^{-1}$ in this spectra range.

\section{After irradiation}

As it can be observed from Fig. 1(b) after irradiation, there are more and more complicated defects in $\mathrm{Si}$. The O-vacancy $(V O)$ pair gives rise to two IR bands, one at $830 \mathrm{~cm}^{-1}$ (neutral charge state) (refer to Fig. 1(b)) and one at $885 \mathrm{~cm}^{-1}$ (negative charge state) ${ }^{31}$ At $\sim 300{ }^{\circ} \mathrm{C}$, the defect becomes unstable and an important percentage of it is converted to the $\mathrm{VO}_{2}$ defect.
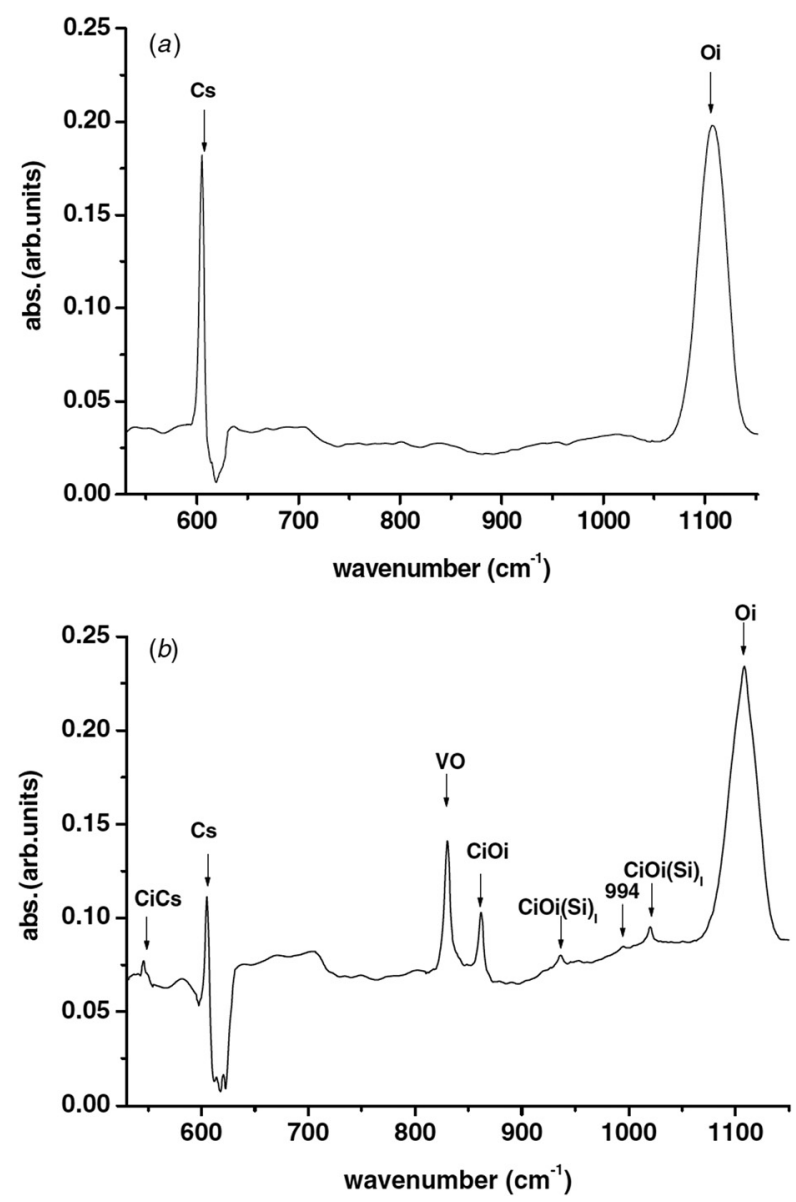

FIG. 1. Typical IR spectrum of the sample (a) prior and (b) after irradiation. Reprinted with permission from Londos et al., Semicond. Sci. Technol. 24, 075002 (2009). Copyright 2009 Institute of Physics. 
The $\mathrm{C}$ interstitial-O interstitial pair gives rise $^{32}$ to a number IR bands the most important being that at $\sim 862 \mathrm{~cm}^{-1}$ depicted in the spectra (refer to Fig. 1(b)). At $\sim 300{ }^{\circ} \mathrm{C}$, the defect becomes unstable and dissociates although a small part of it is converted to the $\mathrm{C}_{\mathrm{s}} \mathrm{O}_{2 \mathrm{i}}$ defect, by pairing with the $V O$ defect which anneals out at the same temperature. $^{32}$

The $\mathrm{C}$ interstitial- $\mathrm{C}$ substitutional pair gives rise to a number IR bands. ${ }^{33,34}$ These bands are very weak detected mainly at cryogenic temperatures. The most important is that at $\sim 546 \mathrm{~cm}^{-1}$ detected also at room temperatures and depicted in our spectra (refer to Fig. 1(b)). In essence, the latter band has the contribution of another band ${ }^{35}$ in the same region from the $\mathrm{C}_{\mathrm{i}} \mathrm{O}_{\mathrm{i}}$ defect. The defect anneals out by dissociation $\sim 250^{\circ} \mathrm{C}$ following a complicated reaction kinetics which is not completely investigated so far. ${ }^{32}$

The $\mathrm{C}_{\mathrm{i}} \mathrm{O}_{\mathrm{i}} \mathrm{Si}_{\mathrm{i}}$ defect gives rise ${ }^{27}$ to two bands at 936 and $1020 \mathrm{~cm}^{-1}$ depicted in the spectra (refer to Fig. 1(b)). In room temperature measurements, the two bands are stable up to $\sim 150^{\circ} \mathrm{C}$ and then disappear without being followed by the emergence of other bands in the spectra. Notably, in low temperature measurements, ${ }^{36}$ the above two bands detected at 940 and $1024 \mathrm{~cm}^{-1}$, respectively, begin to decay in the spectra at $\sim 150^{\circ} \mathrm{C}$ followed by the emergence of three bands at 724,952 , and $973 \mathrm{~cm}^{-1}$ which at $\sim 250^{\circ} \mathrm{C}$ begin to decay followed by three other bands at 959, 969 and $977 \mathrm{~cm}^{-1}$. The latter two sets of bands were attributed ${ }^{36}$ to metastable configurations of the $\mathrm{C}_{\mathrm{i}} \mathrm{O}_{\mathrm{i}} \mathrm{Si}_{\mathrm{I}}$ complex. However, theoretical studies ${ }^{37,38}$ do not confirm these assignments. The issue has not been finally resolved so far pending further investigation.

\section{Impact of isochronal annealing}

The isochronal annealing of irradiated Si leads to the evolution and production of the defects. The isochronal annealing in the temperature range between 100 and $300{ }^{\circ} \mathrm{C}$ leads to the formation of the $V_{2} \mathrm{O}$ and $V_{3} \mathrm{O}$ defects mainly due to the reactions $\mathrm{VO}+V \rightarrow V_{2} \mathrm{O}$ and $\mathrm{VO}+V_{2} \rightarrow V_{3} \mathrm{O}$, respectively. The two defects give rise to IR bands in the spectral range of the $V O$ defect, and their contribution is found by Lorentzian profile. In particular, $V_{2} \mathrm{O}$ defect gives rise to an IR band at $\sim 826 \mathrm{~cm}^{-1}$ and $V_{3} \mathrm{O}$ defect to an IR band at $\sim 839 \mathrm{~cm}^{-1} .{ }^{29}$

Upon isochronal annealing at $\sim 300^{\circ} \mathrm{C}$, the vacancydioxygen $\left(\mathrm{VO}_{2}\right)$ and the $\mathrm{C}$ substitutional-dioxygen interstitial $\left(\mathrm{C}_{\mathrm{s}} \mathrm{O}_{2 \mathrm{i}}\right)$ give rise to IR bands at $\sim 885 \mathrm{~cm}^{-1}$ and $1048 \mathrm{~cm}^{-1}$, respectively (refer to Fig. 1(c) of Ref. 39). The formation of the $V \mathrm{O}_{2}$ and $\mathrm{C}_{\mathrm{s}} \mathrm{O}_{2 \mathrm{i}}$ defects is mainly due to the reactions $V \mathrm{O}+\mathrm{O}_{\mathrm{i}} \rightarrow V \mathrm{O}_{2}$ and $\mathrm{C}_{\mathrm{i}} \mathrm{O}_{\mathrm{i}}+V \mathrm{O}_{\mathrm{i}} \rightarrow \mathrm{C}_{\mathrm{s}} \mathrm{O}_{2 \mathrm{i}}$. The $V \mathrm{O}_{2}$ defect is stable up to $\sim 450^{\circ} \mathrm{C}$, where it begins to anneal out converting to the $V \mathrm{O}_{3}$ defect. The signal from $\mathrm{C}_{\mathrm{s}} \mathrm{O}_{2 \mathrm{i}}$ defect begins to decay from the spectra just above $400{ }^{\circ} \mathrm{C}$ and disappears around $550^{\circ} \mathrm{C}$ without giving rise to any other peaks in the spectra.

Upon isochronal annealing at $\sim 500^{\circ} \mathrm{C}$ the vacancytrioxygen $\left(\mathrm{VO}_{3}\right)$ defect gives rise (Refs. 27 and 28 and references therein) to three IR bands at $\sim 904,968$, and $1000 \mathrm{~cm}^{-1}$. The defect is stable up to $\sim 5500^{\circ} \mathrm{C}$, where it converts to $V \mathrm{O}_{4}$ defect (refer to Fig. 2). Thereafter, at $\sim 580^{\circ} \mathrm{C}$, the vacancy-tetraoxygen $\left(V \mathrm{O}_{4}\right)$ defect gives rise (Refs. 27 and 28 and references therein) to two IR bands at $\sim 985$ and $1010 \mathrm{~cm}^{-1}$. The defect is stable up to $\sim 650^{\circ} \mathrm{C}$ where it converts to vacancy-pentaoxygen defect $\left(V \mathrm{O}_{5}\right)$ defect. Also at about this temperature signals from $V_{\mathrm{m}} \mathrm{O}_{\mathrm{n}} /$ $V \mathrm{O}_{\mathrm{n}} \mathrm{C}_{\mathrm{s}}$ defects appear in the spectra. In particular, the $V \mathrm{O}_{5}$ gives rise to IR bands at $\sim 1037$ and $1051 \mathrm{~cm}^{-1}$, whereas three other bands at a $\sim 762,967$, and $1005 \mathrm{~cm}^{-1}$ have been associated either with $V_{\mathrm{m}} \mathrm{O}_{\mathrm{n}}$ complexes or with the $V \mathrm{O}_{\mathrm{n}} \mathrm{C}_{\mathrm{s}}$ defect (Refs. 27 and 28 and references therein).

\section{B. Oxygen}

Oxygen impurities, which are electrically neutral, occupy interstitial sites $\left(\mathrm{O}_{\mathrm{i}}\right)$ within the $\mathrm{Si}$. In the infrared spectra of $\mathrm{Si}$, there are a number of localized vibrational modes associated ${ }^{40-43}$ with $\mathrm{O}$ in the frequency range of $25-1835 \mathrm{~cm}^{-1}$. These bands with the associated normal modes responsible for them are at: $29 \mathrm{~cm}^{-1}$, at LHe T (ascribed to a low frequency vibration of the $\mathrm{O}$ atom in the (111) plane perpendicular to the $\mathrm{Si}$...Si broken bond), $1136 \mathrm{~cm}^{-1}$, at LHe T (ascribed to the $\nu_{3}$ antisymmetric mode of the Si-O-Si pseudo-molecule), two bands at 515 and $1205 \mathrm{~cm}^{-1}$, at LHe T (ascribed, respectively, to the symmetric modes $\nu_{2}$ and $\nu_{1}$ of the Si-O-Si pseudo-molecule), $1749 \mathrm{~cm}^{-1}$ (attributed to a combination band involving $\mathrm{O}_{\mathrm{i}}$ ), as well as some weak bands as the $560 \mathrm{~cm}^{-1}$ band appearing only at room temperature, another one at $648 \mathrm{~cm}^{-1}$, at $\mathrm{LHe}$ $\mathrm{T}$, and two others at $1819.5 \mathrm{~cm}^{-1}$ and $1831.3 \mathrm{~cm}^{-1}$. The most important band is at $1106 \mathrm{~cm}^{-1}$, from which the $\mathrm{O}$ concentration in $\mathrm{Si}$ is calculated using a calibration coefficient of $3.14 \times 10^{17} \mathrm{~cm}^{-2}$.

For completeness, considering Ge which is the end member of $\mathrm{Si}_{1-\mathrm{x}} \mathrm{Ge}_{\mathrm{x}}$ and isostructural to $\mathrm{Si}, \mathrm{O}$ can also contribute in defect processes, however, its impact is less significant than in $\mathrm{Si}$. This is because in Czochralski-grown Ge the concentration of $\mathrm{O}$ is not as high as in $\mathrm{Si}^{4}{ }^{4}$ At any rate, the experimental solubility of $\mathrm{O}$ in $\mathrm{Ge}$ is high (around $10^{18} \mathrm{~cm}^{-3}$ ) and $\mathrm{O}$ can also be introduced in $\mathrm{Ge}$ when $\mathrm{H}_{2} \mathrm{O}$ vapour or oxygen gas is present in the growth atmosphere or through diffusion at the Ge/oxide interfaces in devices. ${ }^{4} \mathrm{O}_{\mathrm{i}}$ are electrically inactive in $\mathrm{Ge}$, but they may bind with $V$ to form A-centers.

\section{The A-center}

Considering Si upon irradiation at room temperature, the vacancies and self-interstitials which form are very mobile and most of them are destroyed via the reaction $V+\mathrm{Si}_{I}$ $\rightarrow 0$. The surviving vacancies form either $V_{2}$ or if they are captured by $\mathrm{O}_{\mathrm{i}}$ they form $V \mathrm{O}$. The $V \mathrm{O}$ defect has a $\mathrm{C}_{2 v}$ symmetry with the $\mathrm{O}$ atom being attached to the dangling bonds across the $V$. In essence, the $\mathrm{O}$ atom forms a Si-O-Si molecule. The other two Si atoms form a weak Si-Si molecular bond (refer to Fig. 3 and Ref. 14) that has the capacity of trapping an electron and is responsible for the electrical activity of the defect. This is the negative charge state of the defect structure that was proposed by EPR measurements more than five decades ago. ${ }^{44}$ These EPR measurements ${ }^{44}$ 

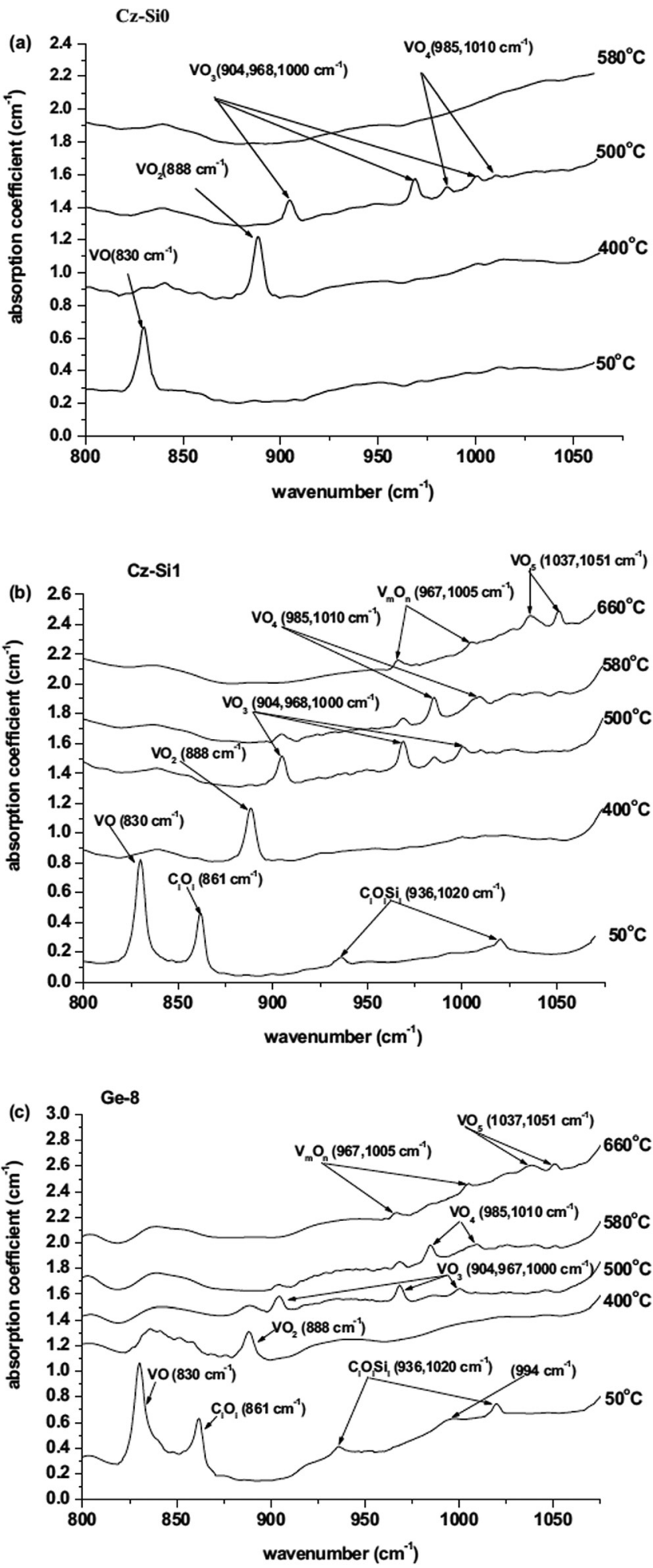

FIG. 2. IR spectra of Si samples with (a) $\mathrm{C}$ after irradiation $\left(\left[\mathrm{C}_{\mathrm{s}}\right]_{\text {af.ir }}\right.$ ) below the detection limit (b) $\left[\mathrm{C}_{\mathrm{s}}\right]_{\mathrm{af} . \mathrm{ir}}=9.92 \times 10^{16} \mathrm{~cm}^{-3}$ and (c) $\left[\mathrm{C}_{\mathrm{s}}\right]_{\mathrm{af} . \mathrm{ir}}=10^{17} \mathrm{~cm}^{-3}$ and $[\mathrm{Ge}]=2 \times 10^{20} \mathrm{~cm}^{-3}$. The IR spectra were recorded after irradiation and at various selective temperatures Reprinted with permission from J. Appl. Phys. 109, 033508 (2011). Copyright 2011 AIP Publishing LLC.

determined that the wavefunction of the unpaired electron is highly localized, ( $\sim 70 \%$ on the $\mathrm{Si}-\mathrm{Si}$ bond) leading to an acceptor level at $\mathrm{E}_{\mathrm{c}}-0.17 \mathrm{eV}$ in the band gap in agreement with electrical studies. ${ }^{44}$ Uniaxial stress studies determined ${ }^{41}$ that the $V O$ defect has a neutral charge state with a similar

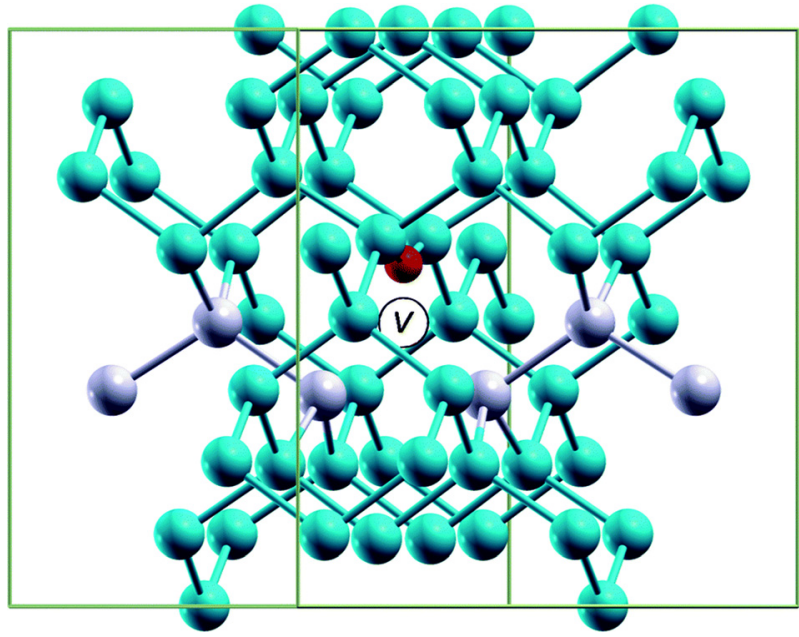

FIG. 3. A schematic of the $V O$ defect. Medium blue spheres are the $\mathrm{Si}$ atoms, and the small red sphere is the $\mathrm{O}$ atom. $\mathrm{Si}$ atoms along the (10-1) direction are highlighted. Reproduced with permission from Wang et al., Phys. Chem. Chem. Phys. 16, 8487 (2014). Copyright 2014 Royal Society of Chemistry.

structure. Interestingly, recent hybrid functional DFT calculations $^{45}$ showed that the A-center can form in the double negative charge state (refer to Sec. VIB). In the A-center, the $\mathrm{O}$ atom is not at a substitutional site but is slightly away ( $\sim 0.9 \AA)$ from the vacancy site along the $\langle 100\rangle$ direction. ${ }^{46}$ DFT calculations by Coutinho et al. ${ }^{47}$ calculated that in the negative charge state the $\mathrm{O}$ atom is displaced away from the reconstructed bond. This is consistent with the picture that the additional electron is trapped in this bond and repels the negatively polarized $\mathrm{O}$ atom. The higher Local Vibration Mode (LVM) frequency in comparison to that of the neutral charge state can be traced to the compression of the bonds around the $\mathrm{O}_{\mathrm{i}}$ atom. Finally, the two bands at 1370 and $1430 \mathrm{~cm}^{-1}$ were assigned ${ }^{48}$ to a combination of the antisymmetric $\mathrm{B}_{1}$ stretching mode and the symmetric stretching mode $A_{1}$ in the two charge states, respectively, of the Acenter.

Again for completeness, considering Ge the A-centers have been studied experimentally ${ }^{8-10}$ and theoretically. ${ }^{7,47}$ In previous DFT work, the A-center was calculated to have a binding energy of -0.36 to $-0.45 \mathrm{eV}$ (Refs. 7 and 47 ), and this small energy difference is justifiable by the different methods used in these DFT studies. What is important is that the A-center in Ge has a far small binding energy (as compared to $\mathrm{Si}$ ), and this will imply that its concentration and impact will be smaller. This will in turn impact the defect processes of A-centers in Ge-rich $\mathrm{Si}_{1-\mathrm{x}} \mathrm{Ge}_{\mathrm{x}}$ alloys.

\section{The $\mathrm{VO}_{2}$ defect}

In irradiated $\mathrm{Si}$ the $\mathrm{VO}_{2}$ defect is formed at temperatures $\sim 300^{\circ} \mathrm{C}$ as the $\mathrm{VO}$ centre migrates and is trapped by an $\mathrm{O}$ atom via the reaction $\left(V \mathrm{O}+\mathrm{O}_{\mathrm{i}} \rightarrow V \mathrm{O}_{2}\right) . V \mathrm{O}_{2}$ structure has $\mathrm{D}_{2 \mathrm{~d}}$ symmetry and the two $\mathrm{O}_{\mathrm{i}}$ share equivalently the vacant site. Every $\mathrm{O}_{\mathrm{i}}$ is bonded with two $\mathrm{Si}$ atoms and the $\mathrm{O}-\mathrm{V}$ distance increases in the $\mathrm{VO}_{2}$ defect as compared to the Acenter. Additionally, as two $\mathrm{O}$ atoms are accommodated in a vacancy, the lengths of the $\mathrm{Si}-\mathrm{O}$ bonds become shorter in 
$V \mathrm{O}_{2}$ as compared to the $V \mathrm{O}$ defect. The consequence is the higher vibrating frequency (LVM frequency for $V \mathrm{O}_{2}$ is $\sim 888 \mathrm{~cm}^{-1}$ which is higher than that of $\sim 830 \mathrm{~cm}^{-1}$ of the $V O$ defect). Finally, as the two $\mathrm{O}_{\mathrm{i}}$ in $V \mathrm{O}_{2}$ saturate all four dangling bonds of the vacancy the defect is electrically inactive.

\section{The $V_{m} O_{n}$ defects}

Upon thermal annealing, vacancies and $\mathrm{O}$ interstitial associate with $V O$ converting it to $V_{\mathrm{m}} \mathrm{O}_{\mathrm{n}}$ defects. These are important as $V_{\mathrm{m}} \mathrm{O}_{\mathrm{n}}$ defects cause leakage currents in $p$ - $n$ junctions. ${ }^{49-51}$ Additionally, the $V_{2} \mathrm{O}$ and $V_{3} \mathrm{O}$ defects have been determined to be recombination centers contributing in the reduction of the minority carriers lifetime induced by irradiation. ${ }^{52}$ Large $V \mathrm{O}_{\mathrm{n}}(\mathrm{n}=4,5,6)$ clusters may act as heterogeneous nuclei enhance oxygen precipitation in irradiated $\mathrm{Si}^{53-56}$

\section{Carbon}

$\mathrm{C}$ is introduced in the Si lattice during crystal growth. In particular, it is incorporated from the polycrystalline starting material, gaseous contaminants during the growth process and graphitic components in the equipment. ${ }^{57-60}$ The introduction of $\mathrm{C}$ leads to local strain due to its small size as compared to Si. It should be noted that when $\mathrm{C}$ occupies substitutional sites $\left(\mathrm{C}_{\mathrm{s}}\right)$, it is electrically neutral as it is isovalent with $\mathrm{Si}$ (or Ge). C in infrared spectra is observed by a localized vibrational mode at $607 \mathrm{~cm}^{-1}$ in $\mathrm{Si}$. $\mathrm{C}$ and $\mathrm{O}$ are highly electronegative and are chemically very reactive. Consequently, they form bonds with $\mathrm{Si}$ atoms, other defects, and dopants.

Upon irradiation, vacancies and $\mathrm{Si}$ interstitial $\left(\mathrm{Si}_{\mathrm{I}}\right)$ atoms are formed at non-equilibrium concentrations. Most of these $\mathrm{Si}_{\mathrm{I}}$ are trapped by $\mathrm{C}_{\mathrm{S}}$, which are pushed to interstitial sites according to $\mathrm{C}_{\mathrm{S}}+\mathrm{Si}_{\mathrm{I}} \rightarrow \mathrm{C}_{\mathrm{i}}$ (known as the Watkins displacement reaction). ${ }^{61,62} \mathrm{C}_{i}$ has been related to the two localized vibrational modes at 922 and $932 \mathrm{~cm}^{-1}$ with this defect in low temperature irradiated $\mathrm{Si}^{63}$ whereas it is established it introduces in-gap states. ${ }^{64} \mathrm{C}_{\mathrm{i}}$ is unstable at room temperature as it migrates and interacts with $\mathrm{O}_{\mathrm{i}}$ and $\mathrm{C}_{\mathrm{s}}$ to form $\mathrm{C}_{\mathrm{i}} \mathrm{O}_{\mathrm{i}}$ and $\mathrm{C}_{\mathrm{i}} \mathrm{C}_{\mathrm{s}}$ defects, respectively. Regarding the $\mathrm{C}_{\mathrm{i}} \mathrm{O}_{\mathrm{i}}$ defect, it has been correlated with at least six localized vibrational modes with the most significant one appearing at $865 \mathrm{~cm}^{-1} .^{27,65}$ Considering $\mathrm{C}_{\mathrm{i}} \mathrm{C}_{\mathrm{s}}$ defect, it is considered to be bistable with at least eleven localized vibrational modes being correlated with it mainly by low temperature measurements (exception being the one at $544 \mathrm{~cm}^{-1}$ that can be also observed at room temperatures). ${ }^{33,34} \mathrm{~A}$ third $\mathrm{C}_{\mathrm{i}} \mathrm{C}_{\mathrm{s}}$ configuration, the $\langle 100\rangle \mathrm{C}-\mathrm{C}$ dumbbell, was proposed by Liu et al. ${ }^{66}$ using both theoretical and experimental investigations. Liu et al. ${ }^{66}$ calculated that this configuration is energetically favourable as compared to the two bistable structures. The structure and properties of these three configurations in $\mathrm{Si}$ were recently studied by Wang et al. ${ }^{67}$ using hybrid functional DFT and the conclusions were consistent with Liu et al. ${ }^{33,34,66}$ (refer also to Sec. VIC) for more information and comparison between the three $\mathrm{C}_{\mathrm{i}} \mathrm{C}_{\mathrm{s}}$ configurations). The community is interested in the $\mathrm{C}_{\mathrm{i}} \mathrm{O}_{\mathrm{i}}$ and $\mathrm{C}_{\mathrm{i}} \mathrm{C}_{\mathrm{s}}$ defects as they introduce states in the $\mathrm{Si}$ band gap and are affecting the operation of devices. ${ }^{68}$ Thus, numerous experimental and theoretical studies were performed to investigate their structure, properties and applications (for example, $\mathrm{C}_{\mathrm{i}} \mathrm{C}_{\mathrm{s}}$ is used to improve $\mathrm{Si}$ optical emitters). ${ }^{69-74}$

From a fundamental viewpoint and under the course of irradiation C-related defects such as $\mathrm{C}_{\mathrm{i}}, \mathrm{C}_{\mathrm{i}} \mathrm{O}_{\mathrm{i}}$, and $\mathrm{C}_{\mathrm{i}} \mathrm{C}_{\mathrm{s}}$, defects can act as nucleation centers for $\mathrm{Si}_{\mathrm{I}}$ to form complexes such as $\mathrm{C}_{\mathrm{i}}\left(\mathrm{Si}_{\mathrm{I}}\right)$ (IR bands at $953 \mathrm{~cm}^{-1}$ and $966 \mathrm{~cm}^{-1}$ ), $\mathrm{C}_{\mathrm{i}} \mathrm{O}_{\mathrm{i}}\left(\mathrm{Si}_{\mathrm{I}}\right)$ (IR bands at $940 \mathrm{~cm}^{-1}$ and $1024 \mathrm{~cm}^{-1}$ ), and $\mathrm{C}_{\mathrm{i}} \mathrm{C}_{\mathrm{s}}\left(\mathrm{Si}_{\mathrm{I}}\right)$ (IR bands at 987 and $993 \mathrm{~cm}^{-1}$ ), respectively. ${ }^{35,37,38,75,76}$ These complexes can be very important as, for example, the $\mathrm{C}_{\mathrm{i}}\left(\mathrm{Si}_{\mathrm{I}}\right)$ can impact the transient enhanced diffusion of boron. ${ }^{75}$

\section{OXYGEN DIFFUSION PROCESSES IN Si}

$\mathrm{O}$ in $\mathrm{Si}$ can be considered as both beneficial and deleterious as it can form electrically active defect centers, O precipitates act as gettering centers for metallic impurities, and can immobilize dislocations improving the mechanical strength of wafers. ${ }^{77-81}$ Understanding $\mathrm{O}$ diffusion is fundamentally important to control defect processes in Czochralski $\mathrm{Si}$ and Ge.

Numerous O-related species have been previously considered to be the diffusing species (including $\mathrm{O}_{\mathrm{i}}$ trimmers, long $\mathrm{O}_{\mathrm{i}}$ chains, and molecular oxygen), ${ }^{82-85}$ however, it is now established that their contribution to the $\mathrm{O}$ diffusion processes is insignificant. ${ }^{86-89}$ The diffusion of oxygen is mainly via $\mathrm{O}_{\mathrm{i}}$ and $\mathrm{O}_{2 \mathrm{i}}$ species as described in a recent DFT study by Timerkaeva et al. ${ }^{88}$ Regarding the $\mathrm{O}_{\mathrm{i}}$ at the ground state configuration, the $\mathrm{O}$ atom is bonded to two neighbouring $\mathrm{Si}$ atoms $\left(\mathrm{Si}^{1}\right.$ and $\mathrm{Si}^{2}$, refer to Fig. 4(a)) and the remaining valence electrons form two lone pairs on the $\mathrm{O}$ atom. ${ }^{88}$ At the saddle configuration, the $\mathrm{O}$ atom is bonded to three $\mathrm{Si}$ atoms $\left(\mathrm{Si}^{1}, \mathrm{Si}^{2}\right.$, and $\mathrm{Si}^{3}$, refer to Fig. $\left.4(\mathrm{~b})\right)$ and the remaining valence electrons form a lone pair on the $\mathrm{O}$, whereas the last electron is localized in a lone pair near the $\mathrm{Si}^{2}$ atom (denoted by an arrow in Fig. 4(b)). ${ }^{88}$ Figs. 4(c) and 4(d) refer to the $\mathrm{O}_{2}$ diffusion ground state and saddle point. The important feature is that both $\mathrm{O}$ atoms diffuse in the same (110) plane, where they are bonded to Si atoms. ${ }^{88}$ In the ground state configuration, each $\mathrm{O}$ atom has a couple of lone pairs. ${ }^{88}$

Regarding the vacancy-O defects, $V O$ has been proposed to act as a species enhancing $\mathrm{O}$ diffusion. ${ }^{90,91}$ Previous studies have inferred that the formation and rapid dissociation of $V \mathrm{O}$ defects may account for the enhanced $\mathrm{O}$ diffusion in annealed $\mathrm{Si}$ by reducing the barrier of $\mathrm{O}$ diffusion jumps in the $\mathrm{Si}$ lattice. Monte Carlo simulations ${ }^{92}$ show that $\mathrm{O}$ can impact the aggregation of vacancies during crystal growth through the formation of O-vacancy defects. ${ }^{93}$

\section{POINT DEFECT ENGINEERING STRATEGIES TO RESTRAIN OXYGEN DIFFUSION IN Si}

\section{A. Background}

Many defect engineering strategies have been proposed to eliminate the deleterious impact of defects, dopants, or their respective clusters in $\mathrm{Si}$ and related materials such as 




FIG. 4. (a) and (b) The O diffusion ground state and saddle point, and (c) and (d) the $\mathrm{O}_{2}$ diffusion ground state and saddle point. Black and red balls represent $\mathrm{Si}$ and $\mathrm{O}$ atoms, respectively. The paths used by $\mathrm{O}$ are represented by a dashed arrow pointing to the final position (gray balls). Reprinted with permission from Appl. Phys. Lett. 103, 251909 (2013). Copyright 2013 AIP Publishing LLC.

Ge. Commonly, the motivation behind these strategies is to introduce other dopants or competing native defects at a sufficient concentration to cancel or control the defect, dopants and their clusters. Interestingly, in a recent study, Bracht et $a l .{ }^{94}$ used proton irradiation to generate a supersaturation of $\mathrm{Ge}$ self-interstitials to annihilate the vacancies in Ge. Under equilibrium conditions, vacancies in Ge are the dominant native point defects that mediate the fast diffusion of $n$-type dopants ( $\mathrm{P}, \mathrm{As}$, or $\mathrm{Sb}$ ) and the formation of large dopant-vacancy clusters. ${ }^{95-97}$ The latter clusters lead to a deactivation of a significant proportion of the dopant profile.

A more common way to control the defect processes in $\mathrm{Si}$ and $\mathrm{Ge}$ is via the introduction of codopants in the lattice. In the example mentioned above, previous studies report the codoping of $n$-type doped $\mathrm{Ge}$ with isovalent atoms ( $\mathrm{C}$ or isovalent atoms including $\mathrm{Sn}$ ) or aliovalent dopants (for example, fluorine) or a second $n$-type dopant. Both DFT and experimental work on isovalent codoping in Ge are consistent revealing that although the transport of $n$-type dopants is constrained the formation of complex dopant-vacancy clusters is not hindered. ${ }^{98,99}$

Previous experimental and DFT studies investigated the impact of $\mathrm{F}$ doping in $\mathrm{Si}^{100-102}$ and Ge. ${ }^{103-105}$ In both materials, doping with $\mathrm{F}$ is an effective way to immobilize the $V$ as $\mathrm{F}$ atoms saturate their dangling bonds ( $\mathrm{F}$ has a very high electronegativity). In essence, this limits the diffusion and association of $V$ with donor atoms, which in turns constrains their diffusion. Additionally, it impacts the formation of extended donor-vacancy clusters. ${ }^{103}$ The recent study of
Jung et al. ${ }^{105}$ concluded that implanted $\mathrm{F}$ atoms passivate the $V$ (at around $500{ }^{\circ} \mathrm{C}$ ) and can lead to an enhancement in Ge-MOSFET performance. ${ }^{105}$ This is an example of how the synergetic use of experiment and DFT can lead to a better understanding and the formulation of a defect engineering strategy in group IV semiconductors. At this point, we should consider the defect engineering strategies applied to limit the formation of the A-center in Si that is doping with large isovalent atoms.

\section{B. Doping with large isovalent atoms}

Of all the possible applications of isovalent doping in $\mathrm{Si}$, none is expected to be more technologically important than its use in photovoltaics. For this reason, the elucidation of the effects of isovalent doping on improving the radiation hardness of $\mathrm{Si}$ continues today to be an exciting area of research. It has been demonstrated that isovalent doping suppresses the formation of O-related and C-related radiation defects in Si, allowing for its application in PV industry.

The community employs similar tactics that is the immobilization of the vacancies. This is because $V$ is the native defect in the A-center and the elimination of the $\mathrm{O}$ concentration is very difficult to achieve in Czochralski grown Si. As in Czochralski grown $\mathrm{Si}$, there is $\mathrm{C}$ that forms clusters that can impact properties, most studies concern oversized isovalent atoms. The introduction of a large isovalent atom in the diamond lattice results in elastic strains in the lattice. This is because of their larger tetrahedral covalent 
radii, compared to that of the host atom. Consider, for example, the introduction of a $\mathrm{Pb}$ atom in the $\mathrm{Si}$ lattice and let the $\Delta \mathrm{r}$ being the difference of the tetrahedral radius between the $\mathrm{Pb}$ and $\mathrm{Si}$ atom $\left(\Delta \mathrm{r}=\mathrm{r}_{\mathrm{Pb}}-\mathrm{r}_{\mathrm{Si}}\right)$. It is expected ${ }^{106}$ that the larger $\mathrm{Pb}$ substitutional atom pushes the first and the second nearest neighbours (NNs) to move radially outwards by $\Delta r_{1}$ and $\Delta \mathrm{r}_{2}$, respectively (and $\Delta \mathrm{r}_{\mathrm{i}}$ for the ith $\mathrm{NN}$ ). Reasonably, $\Delta \mathrm{r}>\Delta \mathrm{r}_{1}>\Delta \mathrm{r}_{2}>\ldots>\Delta \mathrm{r}_{\mathrm{i}}>\ldots$ as a result of the compression of the $\mathrm{Pb}$-Si bonds. For simplicity, the atomistic nature of the displacements beyond the nearest neighbour is neglected, and the Si lattice is described as a continuous medium. In this framework, Hooke's law can be applied to calculate the strain energy stored in the NN of the dopant atoms. This is expressed as ${ }^{106}$

$$
E^{s t}=4 \times \frac{1}{2} g K_{c}\left(\Delta r-\Delta r_{1}\right)^{2}+8 \pi G r_{0}\left(\Delta r_{1}\right)^{2},
$$

where $\mathrm{gK}_{\mathrm{c}}$ is the stiffness constant of the dopant of the first nearest neighbour bonds, $\mathrm{K}_{\mathrm{c}}$ is the force constant, and $\mathrm{g}$ is a dimensionless parameter of order unity. The second term of Eq. (1) represents the energy stored in the surrounding lattice atoms by the expansion of a cavity of radius $r_{0}$ by $\Delta r_{1} \cdot r_{0}$ is the $\mathrm{Si}$ interatomic distance and $\mathrm{G}$ is the $\mathrm{Si}$ shear modulus of elasticity. Equation (1) can be written as ${ }^{106}$

$$
E^{s t}=\text { const } \times(\Delta r)^{2} .
$$

For Si, const has a value of $15 \times 10^{4}$ ergs/atom. ${ }^{106}$

The increase of the tetrahedral radius is calculated by the expression $r=r_{d}-r_{S i}$, where $r_{d}$ is the covalent radius of the impurity atom and $r_{S i}$ is this of a $\mathrm{Si}$ atom $\left(r_{S i}=1.17 \AA\right)$. Thus, for $\mathrm{Pb}\left(\mathrm{r}_{\mathrm{Pb}}=1.44 \AA\right)$, $\mathrm{Sn}\left(\mathrm{r}_{\mathrm{Sn}}=1.41 \AA\right)$, and $\mathrm{Ge}\left(\mathrm{r}_{\mathrm{Ge}}=1.22 \AA\right)$, the corresponding differences are $\Delta \mathrm{r}_{\mathrm{Pb}}=0.27 \AA, \Delta \mathrm{r}_{\mathrm{Sn}}$ $=0.24 \AA$, and $\Delta \mathrm{r}_{\mathrm{Ge}}=0.05 \AA$. Apparently, from Eq. (2), the larger the isovalent dopant, the larger the strain energy.

These strains can be relieved by the association of the dopant with a vacancy. This leads to the dopant vacancy pairs, which are competitive species to the A-centers. Previous studies have discussed how oversized isovalent atoms such as $\mathrm{Sn}$ or $\mathrm{Pb}$ can impact the defect processes in group IV semiconductors. ${ }^{107,108}$

\section{Ge doping in Si}

Ge is only slightly larger than $\mathrm{Si}$, however, it can be an effective trap for vacancies ( $\mathrm{Ge} V$ pairs) below room temperature (RT). At around $180 \mathrm{~K}, \mathrm{GeV}$ defects become unstable and dissociate. ${ }^{107}$ Typically, Ge suppresses the formation and thermal stability of $V \mathrm{O}$, whereas it suppresses the formation but enhances the thermal stability of $V_{2}$ defects. ${ }^{109-111}$ Considering the case of high $\mathrm{Ge}$ content $\mathrm{Si}$, Ge traps selfinterstitials and in essence enhances the A-center concentration. ${ }^{112}$ Importantly, Ge doping has been determined to retard and suppress thermal donor formation ${ }^{112,113}$ stabilizing the electrical properties of Si. Conversely, Ge enhances $^{113,114}$ the generation of $\mathrm{O}$ precipitates, and this can be employed to increase the gettering capability of the material for metallic contaminants. This is important when considering Si for photovoltaic applications. Additionally, Ge doping can improve the mechanical strength of Si by retarding dislocation movement and precipitation. ${ }^{115,116}$

Ge codoping $p$-type or $n$-type dopants affect the photovoltaic properties of $\mathrm{Si}^{117-124}$ Considering B codoping Ge improves segregation redistribution of boron during the thermal oxidation of $\mathrm{Si}$ and importantly limits the formation of boron-O defects. ${ }^{118,119}$ Notably, boron-O defects in solar cells can induce significant degradation of carrier lifetime, leading to a reduction of the energy conversion efficiency of the cell.

Moreover, by Ge doping the mechanical strength of the Si wafer is enhanced. This allows a decrease in the thickness of the wafer which enables the fabrication of thinner $\mathrm{Cz}-\mathrm{Si}$ solar cells, leading to a reduction of their cost. In parallel, the cell efficiency and the photovoltaic module output power under illumination are enhanced. ${ }^{124,125}$

\section{Sn doping in Si}

Sn are larger isovalent dopants compared to Ge and can strongly associate with vacancies, impact the vacancyrelated defects, ${ }^{126-128}$ and influence the generation rate of interstitial-related defects in $\mathrm{Si}^{129-132}$ In recent studies, it was shown that Sn doping can impact the diffusion and formation of A-centers in $\mathrm{Si}^{23,113}$ Critical in this aspect is the formation of $\mathrm{SnVO}$ clusters, which are very bound and less mobile than the $V O{ }^{23}$ Additionally, $\mathrm{Sn} V$ pairs and $\mathrm{SnC}_{\mathrm{i}}$ defects also form in irradiated $\mathrm{Si}$. The latter defect is of importance in the case were $\mathrm{C}$ and $\mathrm{Sn}$ are introduced via codoping in $\mathrm{Si}$ to associate and trap with self-interstitials and vacancies, respectively ( $\mathrm{Sn}$ suppresses both the formation of $V \mathrm{O}$ and $V \mathrm{O}_{2}$ defects). ${ }^{133} \mathrm{Sn}$ atoms capture vacancies and improve the radiation hardness of Si for solar cells and detectors by suppression of the formation of vacancy-related defects and their transformation to larger complexes upon heat treatments. Defects such as $V \mathrm{O}, V \mathrm{O}_{2}$, and $\mathrm{PV}$ (in $n$-type doped $\mathrm{Si}$ ) affect negatively the output and reliability of photovoltaics. Additionally, Sn doping has been investigated as a method to study the impact of vacancies on impurity diffusion and to test diffusion models ${ }^{134}$ (for example, antimony diffusion in $\mathrm{Si}$ ) without modifying the dopant density and hence avoiding considering Fermi level effects. On the other hand, since the interactions of $\mathrm{Sn}$ with $\mathrm{Si}_{\mathrm{I}}$ 's are small, $\mathrm{Sn}$ has been used to study ${ }^{132,135}$ the behavior of $\mathrm{Si}_{\text {I }}$ 's produced by room temperature irradiation. In particularly, the reactions $\mathrm{Si}_{\mathrm{I}}$ 's participate and how they affect the production of C-related defects. Furthermore, Sn due to its electrical neutrality and its larger covalent radius as compared to $\mathrm{Si}$ has been used ${ }^{136,137}$ to compensate the strain layers in $\mathrm{Si}$ doped with high concentrations of donors and acceptors (like $\mathrm{B}$ and $\mathrm{P}$, respectively) of smaller covalent radii than that of Si.

Nevertheless, the formation of $\operatorname{Sn} V$ defects can diminish the impact of Sn for Si hardening as these defects introduce electrical levels in the gap. ${ }^{138-140}$ Importantly, Sn can affect the generation and annealing of $\mathrm{O}$ thermal donors as well as on $\mathrm{O}$ aggregation and precipitation processes in $\mathrm{Si}^{141-143}$ 


\section{Pb doping in Si}

$\mathrm{Pb}$ is a large isovalent dopant, and it has the propensity to attract vacancies (affecting the production of vacancy-O defects) to relieve the strain resulting from its incorporation in the lattice. Interestingly, a signal from the $\mathrm{Pb} V$ pair has not yet been detected. $\mathrm{Pb}$ is usually codoped with $\mathrm{C}$ to relieve the strains in the lattice and can suppress the formation of the $V O$ defect, affecting its thermal stability and reducing its conversion to the $V \mathrm{O}_{2}$ defect. $\mathrm{Pb}$ can also impact the lifetime of nonequilibrium current charge carrier, the formation of thermal donors and $\mathrm{O}$ precipitates.

In particular, $\mathrm{Pb}$ increases the carrier's lifetime, which improves the optoelectronic properties of $\mathrm{Si}$, leading to an enhancement of the performance of polycrystalline Si solar cells. ${ }^{144}$ It deserves noting that $\mathrm{Pb}$ in $\mathrm{Si}$ does not introduce, to the best of our knowledge, any levels from radiationinduced defects in the forbidden gap in comparison with Sn. ${ }^{129,133}$ These levels in Sn-doped Si may act as recombination centers deteriorating the performance of solar cells. In this respect, the absence of such levels in Pd-doped $\mathrm{Si}$ is an advantage in comparison to $\mathrm{Sn}$-doped $\mathrm{Si}$.

\section{OXYGEN RELATED DEFECTS IN SiGe}

\section{A. Background}

The investigation of the A-center and other $\mathrm{O}$ related defects in $\mathrm{Si}_{1-\mathrm{x}} \mathrm{Ge}_{\mathrm{x}}$ is limited as compared to $\mathrm{Si}^{145-147}$ The A-center is also electrically active in $\mathrm{Si}_{1-\mathrm{x}} \mathrm{Ge}_{\mathrm{x}}$, and therefore, it is technologically important to determine its properties. ${ }^{146,147}$ The complication in $\mathrm{Si}_{1-\mathrm{x}} \mathrm{Ge}_{\mathrm{x}}$ is that there are two atom species ( $\mathrm{Si}$ or $\mathrm{Ge}$ ) that can occupy a lattice site and this will result in Si-rich and Ge-rich areas. These in turn can impact the formation of point defects. For example, previous experimental studies determined that $\mathrm{O}$ interstitial atoms preferentially bond with $\mathrm{Si}$ atoms rather than $\mathrm{Ge}$ atoms in $\mathrm{Si}_{1-\mathrm{x}} \mathrm{Ge}_{\mathrm{x} .}{ }^{148,149}$ At any rate, most previous studies were confined to very low Ge-content $\mathrm{Si}_{1-\mathrm{x}} \mathrm{Ge}_{\mathrm{x}}$. Concerning vacancies previous experimental and DFT studies indicated that it is more energetically favourable for the vacancy to form near at least one Ge atom. ${ }^{150,151}$ In particular, the positron annihilation spectroscopy (PAS) investigation of Sihto et $a l .{ }^{150}$ determined that there is energy gain when a Ge atom replaces a $\mathrm{Si}$ atom next to a vacancy in strained $\mathrm{Si}_{1-\mathrm{x}} \mathrm{Ge}_{\mathrm{x}}$ and this was supported by consequent DFT calculations. ${ }^{151}$ Another important aspect is in $\mathrm{Si}_{1-\mathrm{x}} \mathrm{Ge}_{\mathrm{x}}$ is that the Ge content impacts the diffusion of $\mathrm{O}$ and the conversion of the $V \mathrm{O}$ pairs to $V \mathrm{O}_{2}$ clusters. ${ }^{152-154}$

\section{B. Impact of Ge content}

In the study of Sgourou et al., ${ }^{154}$ FTIR spectroscopy was employed to clarify the interactions and in particular, to investigate the production and evolution of A-centers in $n$-type $\mathrm{Si}_{1-\mathrm{x}} \mathrm{Ge}_{\mathrm{x}}$ (where $\mathrm{x}=0,0.025$, and 0.055). Figure 5 represents typical segments of the IR spectra of the $n$-type $\mathrm{Si}_{1-\mathrm{x}} \mathrm{Ge}_{\mathrm{x}}$ (where $\mathrm{x}=0,0.025$, and 0.055 ) crystals recorded after irradiation and at $350^{\circ} \mathrm{C}$ in the course of the 20 -min isochronal anneals sequence. ${ }^{154}$ The two selected temperatures are typical
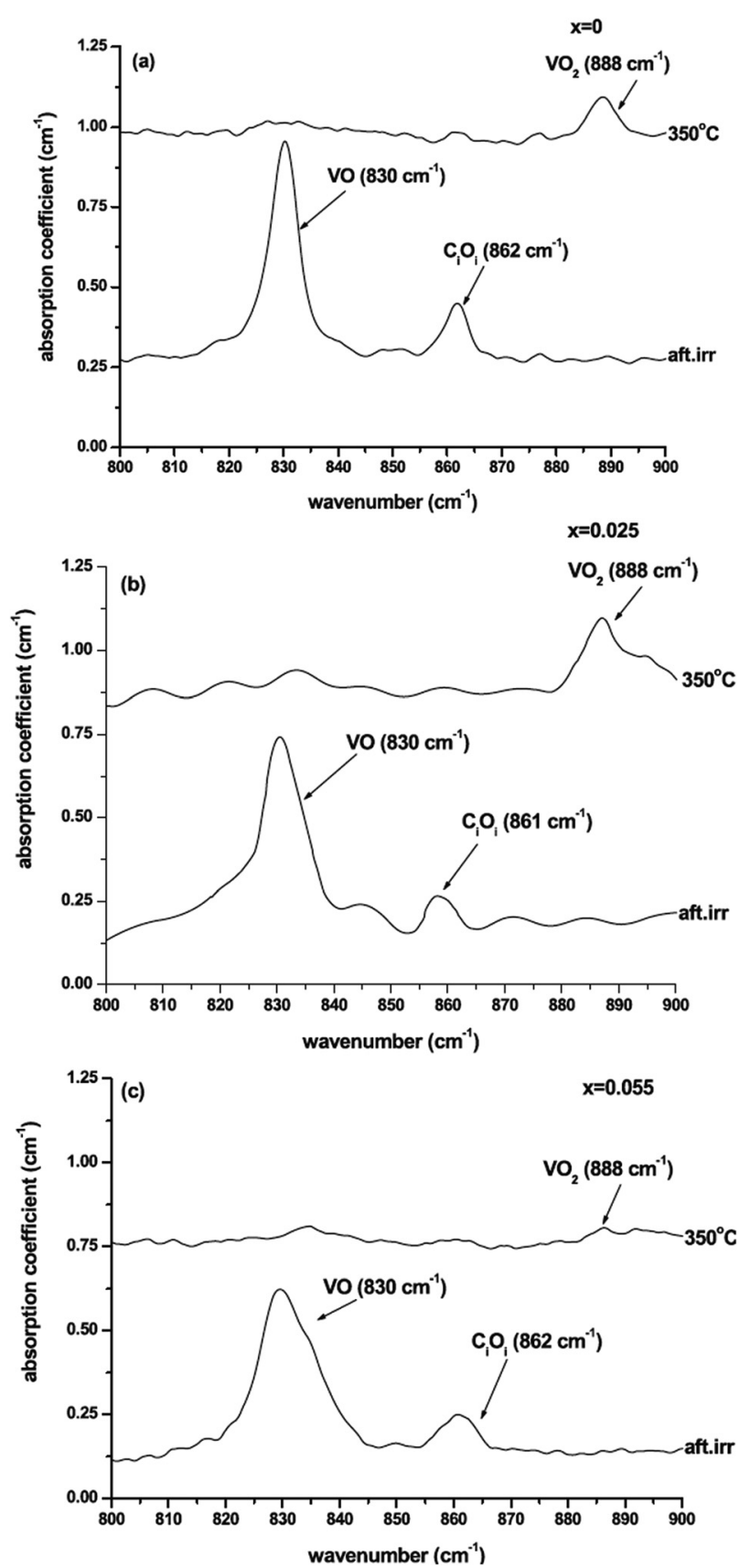

FIG. 5. Typical segments of the IR spectra of the $n$-type $\mathrm{Si}_{1-\mathrm{x}} \mathrm{Ge}_{\mathrm{x}}$ crystals for (a) $\mathrm{x}=0$, (b) $\mathrm{x}=0.025$, and (c) $\mathrm{x}=0.055$ recorded after irradiation at $350^{\circ} \mathrm{C}$, in the course of the 20-min isochronal anneals sequence. Reprinted with permission from J. Appl. Phys. 113, 113507 (2013). Copyright 2013 AIP Publishing LLC.

in exhibiting the evolution of the $V \mathrm{O}$ defect and its conversion to the $V \mathrm{O}_{2}$ defect $\left(V \mathrm{O}+\mathrm{O}_{\mathrm{i}} \rightarrow V \mathrm{O}_{2}\right)$. After irradiation only the $V O$ is present in the spectra in full strength, although at $350^{\circ} \mathrm{C}$ its signal has almost disappeared whereas the signal from the $V \mathrm{O}_{2}$ defect appears quite strong. ${ }^{154}$ The band at $862 \mathrm{~cm}^{-1}$ arising from the $\mathrm{C}_{\mathrm{i}} \mathrm{O}_{\mathrm{i}}$ defect being present after the irradiation also vanishes after the $350{ }^{\circ} \mathrm{C}$ isochronal anneal. ${ }^{154}$ Regarding the $V O$ defect, it is observed that the amplitude of the corresponding band at $830 \mathrm{~cm}^{-1}$ decreases as $\mathrm{x}$ increases from 0 to 0.025 and then to 0.055 , whereas the width of the band increases. ${ }^{154}$ The band becomes wider and its shape distorted indicating the presence of more than one contributor in this spectral range. 
Regarding $V \mathrm{O}_{2}$ defect, it is observed that its amplitude increases at $\mathrm{x}=0.025$ in comparison with that at $\mathrm{x}=0$ and then decreases substantially for $\mathrm{x}=0.055$. $^{154}$

An important feature that was revealed by the FTIR studies is that $V O$ defects have a lower concentration in $\mathrm{Si}_{1-\mathrm{x}} \mathrm{Ge}_{\mathrm{x}}$ and anneal at lower temperatures as compared to $\mathrm{Si}^{154}$ These have been linked to the weaker bonds ( $\mathrm{Si}-\mathrm{Ge}$ and $\mathrm{Ge}-\mathrm{Ge}$ ) that are also present in $\mathrm{Si}_{1-\mathrm{x}} \mathrm{Ge}_{\mathrm{x}}$. In a previous IR study, ${ }^{154}$ Lorentzian analysis was employed to determine that the total VO signal in the spectra is composed by (a) VO surrounded by $\mathrm{Si}$ atoms up to the next nearest neighbour sites, (b) $(V \mathrm{O}-\mathrm{Ge})_{1}$ that is $V \mathrm{O}$ with $\mathrm{Ge}$ atom(s) only at the nearest neighbor site, and (c) $(V \mathrm{O}-\mathrm{Ge})_{2}$ that is $V \mathrm{O}$ with $\mathrm{Ge}$ atom(s) at the next nearest neighbor site. As the binding of $\mathrm{O}$ with $\mathrm{Ge}$ to form the $(V \mathrm{O}-\mathrm{Ge})_{1}$ and $(V \mathrm{O}-\mathrm{Ge})_{2}$ structures is strong, it results to higher annealing temperatures for these defects. ${ }^{154}$ At $180^{\circ} \mathrm{C}$, the A-centers migrate and associate with $\mathrm{Ge}$ atoms in the $\mathrm{Si}_{1-\mathrm{x}} \mathrm{Ge}_{\mathrm{x}}$ lattice. ${ }^{154}$ This temperature is lower as compared to $\mathrm{Si}$. The key to the association is the binding of the $\mathrm{Ge}$ atoms to the vacant site in the $V O$ pair ${ }^{154}$ as is illustrated by the increase of the $(\mathrm{VO}-\mathrm{Ge})_{1}$ and $(\mathrm{VO}-$ $\mathrm{Ge})_{2}$ structures as the $V \mathrm{O}$ defects decrease (refer to Fig. 6).
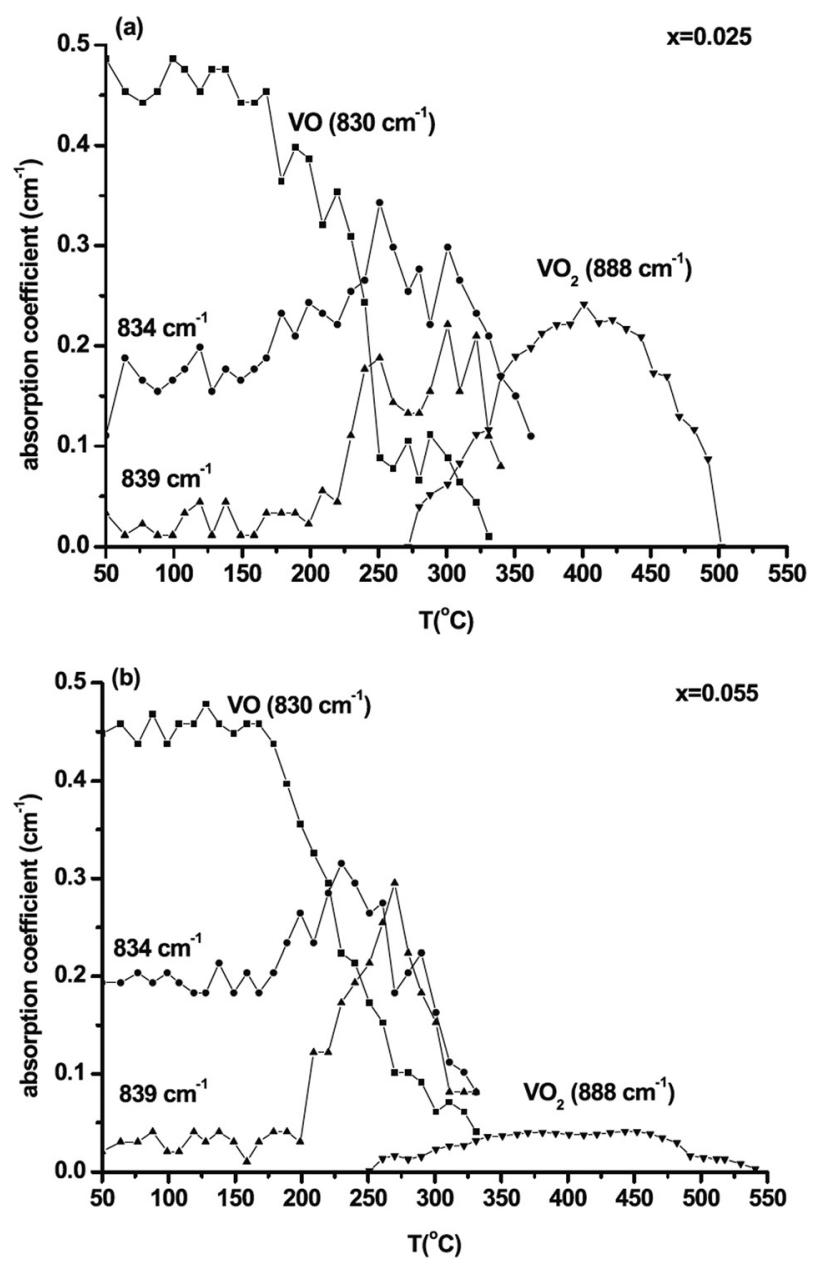

FIG. 6. FTIR results of the evolution of the $V \mathrm{O},(V \mathrm{O}-\mathrm{Ge})_{1}$ and $(V \mathrm{O}-\mathrm{Ge})_{2}$ bands in $n$-type $\mathrm{Si}_{1-\mathrm{x}} \mathrm{Ge}_{\mathrm{x}}$ crystals for (a) $\mathrm{x}=0.025$ and (b) $\mathrm{x}=0.055$ in the course of the $20 \mathrm{~min}$ isochronal anneals sequence. Reprinted with permission from J. Appl. Phys. 113, 113507 (2013). Copyright 2013 AIP Publishing LLC.
At about $250{ }^{\circ} \mathrm{C}$, the $V \mathrm{O}$, the $(V \mathrm{O}-\mathrm{Ge})_{1}$ and $(V \mathrm{O}-\mathrm{Ge})_{2}$ structures anneal out and form the $\mathrm{VO}_{2}$ and $\left(\mathrm{VO}_{2}-\mathrm{Ge}\right)$ defects. ${ }^{154}$ Ge can impact the availability of self-interstitials thus impacting the processes related in the formation of the $\mathrm{VO}_{2}$ defect. Studies of $\mathrm{Ge}$-doped $\mathrm{Si}^{112}$ have concluded that $\mathrm{Ge}$ atoms compete with $\mathrm{C}$ atoms in trapping $\mathrm{Si}_{\mathrm{I}}$ mainly when the concentration of $\mathrm{Ge}$ is at least three orders of magnitude larger than that of $\mathrm{C}$. This is the case for the $\mathrm{Si}_{1-\mathrm{x}} \mathrm{Ge}_{\mathrm{x}}$ material. Notably, the Ge atoms may act as centres of indirect recombination of vacancies and self-interstitials. ${ }^{109,155}$ Therefore, in $\mathrm{Si}_{1-\mathrm{x}} \mathrm{Ge}_{\mathrm{x}}$, the Ge concentration is expected to impact the formation of vacancy-related defects as, for instance, the $V \mathrm{O}_{2}$ centre. It has also been reported ${ }^{110}$ that the Frenkel pair components may be trapped by the strain fields of the Ge atoms, thus affecting the formation of secondary defects. Additionally, Ge can lead to the formation of $\left(\mathrm{VO}_{2-}\right.$ Ge) structures. ${ }^{154}$ With the increase of the Ge content in $\mathrm{Si}_{1-\mathrm{x}} \mathrm{Ge}_{\mathrm{x}}$ material, the alternative reaction channels that may lead to the formation of $V \mathrm{O}_{2}$ defects are substantially suppressed. ${ }^{154}$ Further to this point, it should be added that additional formation of the $\mathrm{VO}_{2}$ centre ${ }^{156}$ through reaction paths as: $V_{2}+\mathrm{O}_{2} \rightarrow V_{2} \mathrm{O}_{2}+\mathrm{Si}_{\mathrm{I}} \rightarrow V \mathrm{O}_{2}$ and $V_{2}+\mathrm{Si}_{\mathrm{I}} \rightarrow$ $V+\mathrm{O}_{2} \rightarrow V \mathrm{O}_{2}$ is expected to be largely restricted in $\mathrm{Si}_{1-\mathrm{x}} \mathrm{Ge}_{\mathrm{x}}$.

\section{INSIGHTS FROM ADVANCED COMPUTATIONAL TECHNIQUES}

\section{A. Background}

Over the past few decades, the ever increasing computational power has allowed the widespread use of atomic scale modeling. The ever decreasing characteristic dimensions of devices and the high concentration of defects and dopants requires methods such as DFT to understand the materials properties. DFT has been employed to investigate $\mathrm{O}$ related defects in group IV semiconductors for a number of years, however, the first studies were plagued by the small number of atoms and the inappropriate description of the exchangecorrelation functionals. Recent studies employ more advanced hybrid functionals (for example, the screened hybrid functionals due to Heyd, Scuseria, and Ernzerhof (HSE06) ${ }^{157,158}$, which are deemed to be more appropriate in the description of the electronic structure of the material. Here, earlier DFT studies within the local density approximation (LDA) or the generalized gradient approximation (GGA) to calculate the relative energetics of defects will also be discussed.

\section{B. A-centers revisited}

Previous experimental studies determined that the Acenter can form at different charge states depending upon the position of the Fermi level in the band gap. ${ }^{41,44}$ Recently, Wang et $a l .{ }^{45}$ used hybrid DFT calculations to study Acenters in Si. Fig. 7 reports the calculated formation energy of the A-center with respect to the Fermi energy for all possible charge states. ${ }^{45}$ It can be deduced from this figure that only that only two charge states of the A-center are important. In particular, the $V \mathrm{O}^{0}$ defect is energetically favourable 




FIG. 7. Hybrid functional DFT formation energies of the A-center with respect to the Fermi energy. Reprinted with permission from Appl. Phys. Lett. 103, 052101 (2013). Copyright 2013 AIP Publishing LLC.

up to a Fermi energy of $0.54 \mathrm{eV}$ and then the $V \mathrm{O}^{-2}$ defect prevails. ${ }^{45}$

How can this difference between experiment and hybrid DFT calculations be justified? Bean and Newman ${ }^{31}$ have determined that the increase of the temperature will lower the position of the Fermi level in the band gap and in effect reduce the $V \mathrm{O}^{-1}$ over $V \mathrm{O}^{0}$ defect fraction. Additionally, it should be considered that DFT results correspond to $0 \mathrm{~K}$, whereas experiment corresponds to far higher temperatures. Pesola et al. ${ }^{159}$ used LDA/DFT and calculated that $V \mathrm{O}^{-2}$ is energetically favourable for Fermi energies above $0.53 \mathrm{eV}$. This is in agreement with the more recent hybrid DFT study of Wang et al. ${ }^{45}$

Through DFT further insights on the A-center can be gained via considering its constituent elements (i.e., $V$ and $\mathrm{O}_{\mathrm{i}}$ ). Fig. 8 reports the formation energies of the $V$ and $\mathrm{O}_{\mathrm{i}}$ defects with respect to the Fermi energy for various charge states. Concerning the $V$ its formation energy is high at low Fermi energy (around $4.5 \mathrm{eV}$ ) and decreases to about $3 \mathrm{eV}$ for the -2 charge state (Ref. 44 and Fig. 8(a)). The -2 charge state is favourable when the Fermi energy is above $0.27 \mathrm{eV} .{ }^{45}$ This implies that under equilibrium conditions $V$ is difficult

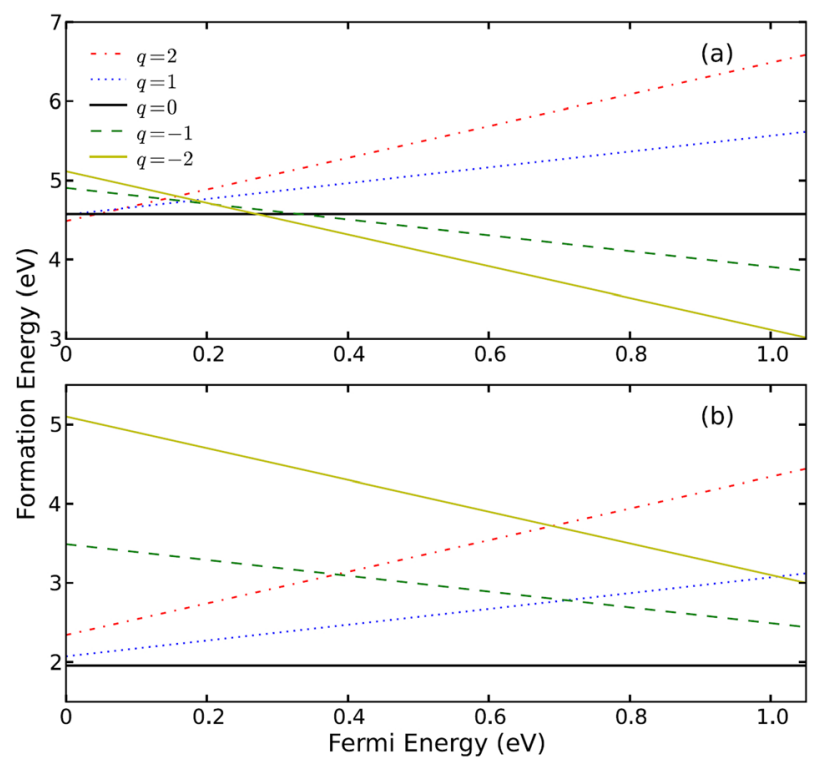

FIG. 8. Hybrid functional DFT formation energies of the (a) $V$ and (b) $\mathrm{O}_{\mathrm{i}}$ defects, with respect to the Fermi energy. Reprinted with permission from Appl. Phys. Lett. 103, 052101 (2013). Copyright 2013 AIP Publishing LLC. to form in the whole Fermi energy range. The high formation energy of Si vacancies is in agreement with experimental evidence from Si crystal growth, Si self-diffusion, high temperature wafer processing, and metal/dopant diffusion experiments. ${ }^{160,161}$ At any rate when considering an irradiation environment, there is a supersaturation of vacancies, which will lead to the formation of A-centers. Concerning the $\mathrm{O}_{\mathrm{i}}$ defect the neutral charge state is dominant (formation energy of $1.95 \mathrm{eV}$ ) (Ref. 45 and Fig. 8(a)).

\section{Carbon related defects}

As in the case of the A-center (discussed above) hybrid DFT calculations were used to study the most important $\mathrm{C}$ related defects. In particular, Wang et al. ${ }^{67}$ investigated the structure and energetics of defect pairs $\left(\mathrm{C}_{\mathrm{i}}\left(\mathrm{Si}_{\mathrm{I}}\right), \mathrm{C}_{\mathrm{i}} \mathrm{O}_{\mathrm{i}}\right.$, and $\mathrm{C}_{\mathrm{i}} \mathrm{C}_{\mathrm{s}}$ ) and defect clusters $\mathrm{C}_{\mathrm{i}} \mathrm{O}_{\mathrm{i}}\left(\mathrm{Si}_{\mathrm{I}}\right)$ ). Fig. 9 reports the structures derived by DFT of the most important $\mathrm{C}$-related defects in Si. Considering the $\mathrm{C}_{\mathrm{i}}\left(\mathrm{Si}_{\mathrm{I}}\right)$ (refer to Fig. 9(a)), the Si-C dumbbell partially shares the interstitial site with the $\mathrm{Si}$ atoms surrounding the defect pair being slightly shifted away from their lattice sites. ${ }^{67}$ In $\mathrm{C}_{\mathrm{i}}\left(\mathrm{Si}_{\mathrm{I}}\right)$, the $\mathrm{C}$ atom is threefold coordinated. Fig. 10(a) reports the formation energies for the $\mathrm{C}_{\mathrm{i}}\left(\mathrm{Si}_{\mathrm{I}}\right)$ defect indicating that the +2 state is prevalent up to high Fermi energy.

The structure of the $\mathrm{C}_{\mathrm{i}} \mathrm{O}_{\mathrm{i}}$ defect given by the hybrid DFT calculations of Wang et al. ${ }^{67}$ is consistent with the results of previous studies. ${ }^{70,162}$ In the $\mathrm{C}_{\mathrm{i}} \mathrm{O}_{\mathrm{i}}$ defect, the $\mathrm{C}_{\mathrm{i}}$ and $\mathrm{O}_{\mathrm{i}}$ interstitials form with $\mathrm{Si}$ a ring (refer to Fig. 9(b)). Fig. 10(b) reports the formation energy of the $\mathrm{C}_{\mathrm{i}} \mathrm{O}_{\mathrm{i}}$ defect as a function of the Fermi energy for different charge states. ${ }^{67}$ It is calculated the lowest energy $\mathrm{C}_{\mathrm{i}} \mathrm{O}_{\mathrm{i}}$ defect changes from the +2 to +1 and then to 0 charge state as the Fermi energy increases. ${ }^{67}$

Figs. 9(e)-9(g) present the three stable configurations of the $\mathrm{C}_{\mathrm{i}} \mathrm{C}_{\mathrm{s}}$ defect. The $\mathrm{A}-\mathrm{C}_{\mathrm{i}} \mathrm{C}_{\mathrm{s}}$ and $\mathrm{B}-\mathrm{C}_{\mathrm{i}} \mathrm{C}_{\mathrm{s}}$ were established decades ago, ${ }^{163,164}$ whereas the $\mathrm{C}-\mathrm{C}_{\mathrm{i}} \mathrm{C}_{\mathrm{s}}$ has been only demonstrated by DFT calculations to be the most stable configuration. ${ }^{165}$ Figs. $10(\mathrm{e})-10(\mathrm{~g})$ report the different charge states of the formation energy of the $\mathrm{C}_{\mathrm{i}} \mathrm{C}_{\mathrm{s}}$ defect as a function of the Fermi energy. As it can be observed from this figure, the neutral charge state dominates the in between Fermi energy range. ${ }^{67}$ At low Fermi energy, the positive charge states are dominant for both the A- and B-type configurations, however, the $\mathrm{A}-\mathrm{C}_{\mathrm{i}} \mathrm{C}_{\mathrm{s}}$ has a higher (1/0) transition level (refer to Figs. 10(e) and 10(f)). For the $\mathrm{C}-\mathrm{C}_{\mathrm{i}} \mathrm{C}_{\mathrm{s}}$ defect, the +2 and -2 charge states are favorable below Fermi energy $0.06 \mathrm{eV}$ and above $0.91 \mathrm{eV}$, respectively.

Figs. 9(c) and 9(d) report the two configurations of $\mathrm{C}_{\mathrm{i}} \mathrm{O}_{\mathrm{i}}\left(\mathrm{Si}_{\mathrm{I}}\right)$, which were previously denoted $\mathrm{C}_{\mathrm{i}} \mathrm{O}_{\mathrm{i}}\left(\mathrm{Si}_{\mathrm{I}}\right)_{\mathrm{a}}$, and $\mathrm{C}_{\mathrm{i}} \mathrm{O}_{\mathrm{i}}\left(\mathrm{Si}_{\mathrm{I}}\right)_{\mathrm{b}}{ }^{67}$ They differ by the $\mathrm{Si}$ interstitial position relative to the $\mathrm{C}_{\mathrm{i}} \mathrm{O}_{\mathrm{i}}$ pair ${ }^{67}$ and are similar to the $\mathrm{C} 4(\mathrm{a})$ and $\mathrm{C} 4(\mathrm{c})$ configurations reported previously by Backlund and Estreicher. ${ }^{38}$ The total energy of $\mathrm{C}_{\mathrm{i}} \mathrm{O}_{\mathrm{i}}\left(\mathrm{Si}_{\mathrm{I}}\right)_{\mathrm{a}}$ is $0.28 \mathrm{eV}$ lower than that of $\mathrm{C}_{\mathrm{i}} \mathrm{O}_{\mathrm{i}}\left(\mathrm{Si}_{\mathrm{I}}\right)_{\mathrm{b}}$ for the $0,-1$, and -2 charge states but $\mathrm{C}_{\mathrm{i}} \mathrm{O}_{\mathrm{i}}\left(\mathrm{Si}_{\mathrm{I}}\right)_{\mathrm{a}}$ is $0.45 \mathrm{eV}$ and $1.51 \mathrm{eV}$ higher in energy as compared to $\mathrm{C}_{\mathrm{i}} \mathrm{O}_{\mathrm{i}}\left(\mathrm{Si}_{\mathrm{I}}\right)_{\mathrm{b}}$ for the +1 and +2 charge state, respectively. ${ }^{67}$ Figs. 10 (c) and 10(d) report the formation energy as a function of the Fermi energy for $\mathrm{C}_{\mathrm{i}} \mathrm{O}_{\mathrm{i}}\left(\mathrm{Si}_{\mathrm{I}}\right)_{\mathrm{a}}$, and $\mathrm{C}_{\mathrm{i}} \mathrm{O}_{\mathrm{i}}\left(\mathrm{Si}_{\mathrm{I}}\right)_{\mathrm{b}}$, 


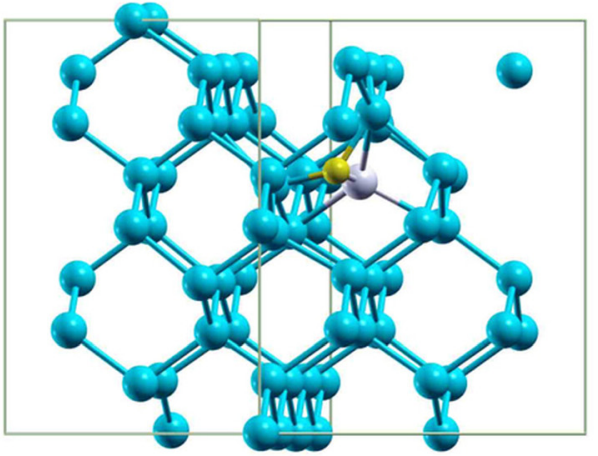

(a)

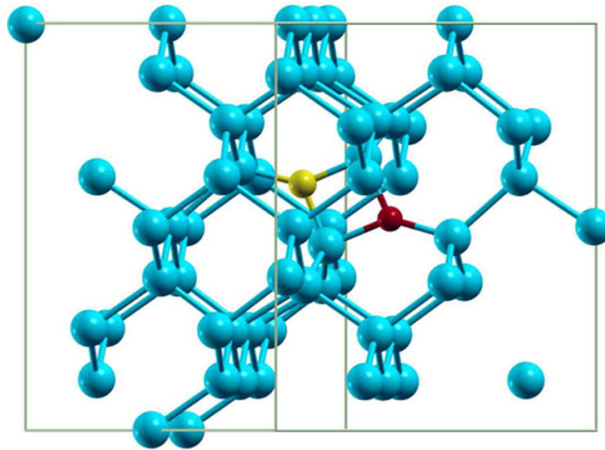

(b)

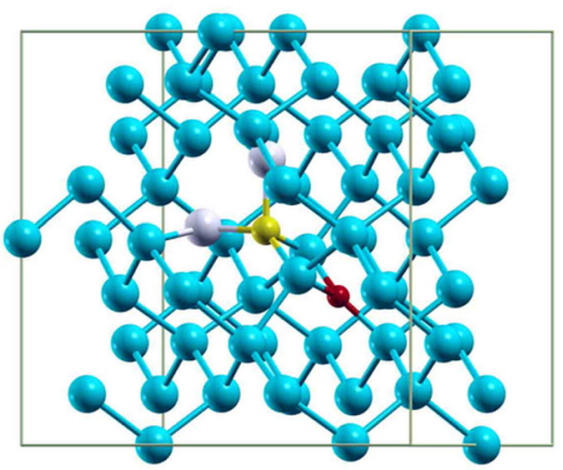

(c)

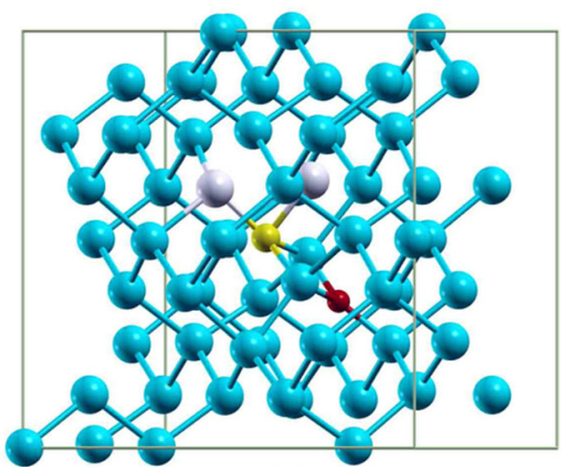

(d)

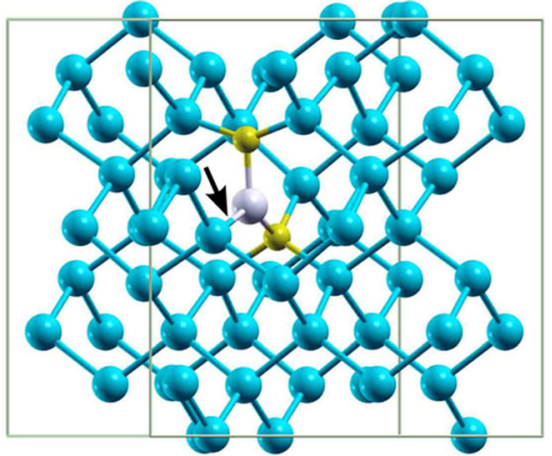

(e)

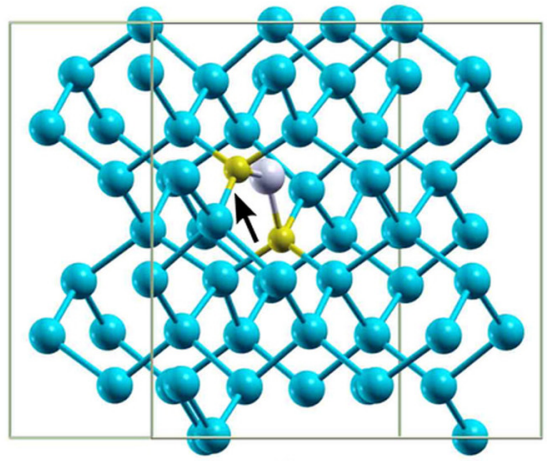

(f)

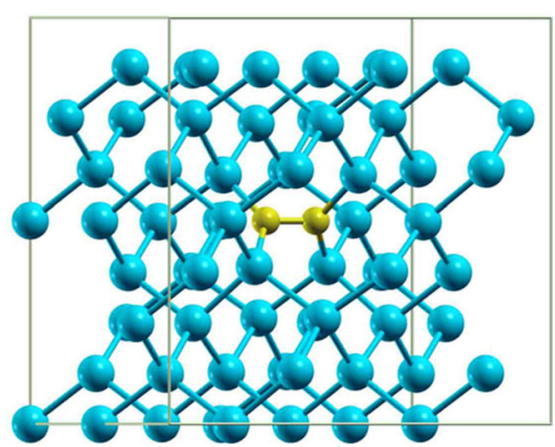

(g)
FIG. 9. The structures derived by DFT of the most important carbon-related defects in Si. (a) $\mathrm{C}_{\mathrm{i}}\left(\mathrm{Si}_{\mathrm{I}}\right)$, (b) $\mathrm{C}_{\mathrm{i}} \mathrm{O}_{\mathrm{i}}$, (c) $\mathrm{C}_{\mathrm{i}} \mathrm{O}_{\mathrm{i}}\left(\mathrm{Si}_{\mathrm{I}}\right)_{a}$, (d) $\mathrm{C}_{\mathrm{i}} \mathrm{O}_{\mathrm{i}}\left(\mathrm{Si}_{\mathrm{I}}\right)_{\mathrm{b}}$, (e) A-type $\mathrm{C}_{\mathrm{i}} \mathrm{C}_{\mathrm{s}}$, (f) B-type $\mathrm{C}_{\mathrm{i}} \mathrm{C}_{\mathrm{s}}$, and (g) C-type $\mathrm{C}_{\mathrm{i}} \mathrm{C}_{\mathrm{s}}$. The big blue spheres represent the $\mathrm{Si}$ atoms, medium yellow spheres the $\mathrm{C}$ atoms, and small red spheres the $\mathrm{O}$ atoms. Grey represents the $\mathrm{Si}_{\mathrm{I}}$ atom in $\mathrm{C}_{\mathrm{i}}\left(\mathrm{Si}_{\mathrm{I}}\right)$, the $\mathrm{Si}$ atom connecting two $\mathrm{C}$ atoms in $\mathrm{A}-\mathrm{C}_{\mathrm{i}} \mathrm{C}_{\mathrm{s}}$ and $\mathrm{B}-\mathrm{C}_{\mathrm{i}} \mathrm{C}_{\mathrm{s}}$, and the two $\mathrm{Si}$ atoms that move significantly between the two $\mathrm{C}_{\mathrm{i}} \mathrm{O}_{\mathrm{i}}\left(\mathrm{Si}_{\mathrm{I}}\right)$ structures. Arrows point to the breaking and forming of bonds during the transition between $\mathrm{A}-\mathrm{C}_{\mathrm{i}} \mathrm{C}_{\mathrm{s}}$ and $\mathrm{B}-\mathrm{C}_{\mathrm{i}} \mathrm{C}_{\mathrm{s}}$. Reprinted with permission from Wang et al., Sci. Rep. 4, 4909 (2014). respectively. The neutral charge state of the $\mathrm{C}_{\mathrm{i}} \mathrm{O}_{\mathrm{i}}\left(\mathrm{Si}_{\mathrm{I}}\right)_{\mathrm{a}}$ has a lower formation energy than the neutral charge state of the $\mathrm{C}_{\mathrm{i}} \mathrm{O}_{\mathrm{i}}\left(\mathrm{Si}_{\mathrm{I}}\right)_{\mathrm{b}}$ defect. ${ }^{67}$ There is a transition from the +2 state into the neutral charge state for $\mathrm{C}_{\mathrm{i}} \mathrm{O}_{\mathrm{i}}\left(\mathrm{Si}_{\mathrm{I}}\right)_{\mathrm{a}}$ as the Fermi energy increases. ${ }^{67}$ Conversely, for the $\mathrm{C}_{\mathrm{i}} \mathrm{O}_{\mathrm{i}}\left(\mathrm{Si}_{\mathrm{I}}\right)_{\mathrm{b}}$ defect the +2 dominates throughout the Fermi energy range. ${ }^{67}$

\section{Insights on isovalent doping}

Previous computational studies have considered and compared the impact of isovalent doping on O-vacancy defects in $\mathrm{Si}$. These studies were not confined to $\mathrm{Ge}, \mathrm{Sn}$, and $\mathrm{Pb}$ for which there was experimental evidence but were extended to large isovalent dopants such as hafnium (Hf). 


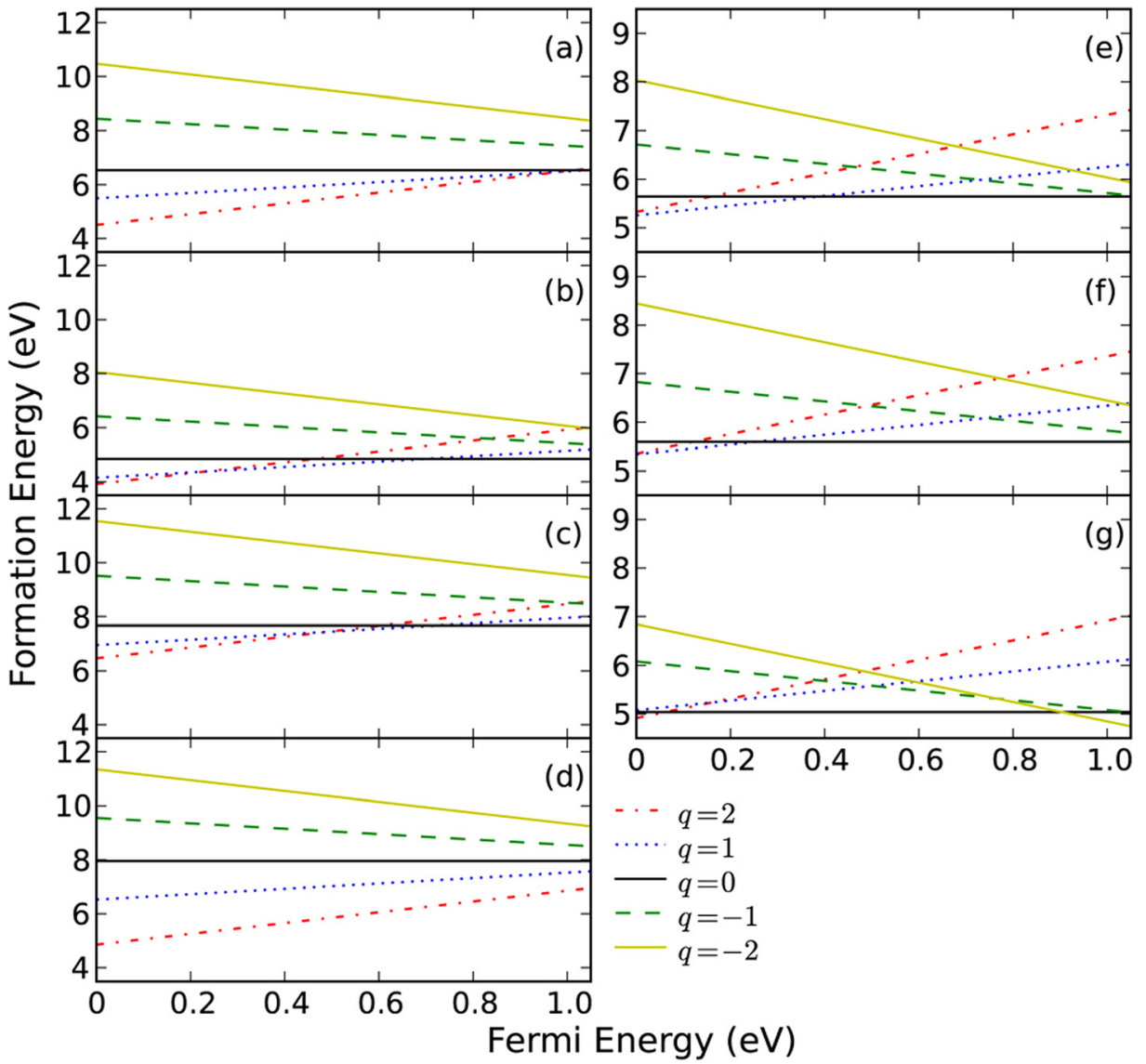

FIG. 10. Hybrid functional DFT formation energies of the (a) $\mathrm{C}_{\mathrm{i}}\left(\mathrm{Si}_{\mathrm{I}}\right)$, (b) $\mathrm{C}_{\mathrm{i}} \mathrm{O}_{\mathrm{i}}$, (c) $\mathrm{C}_{\mathrm{i}} \mathrm{O}_{\mathrm{i}}\left(\mathrm{Si}_{\mathrm{I}}\right)_{\mathrm{a}}$, (d) $\mathrm{C}_{\mathrm{i}} \mathrm{O}_{\mathrm{i}}\left(\mathrm{Si}_{\mathrm{I}}\right)_{\mathrm{b}}$, (e) A-type $\mathrm{C}_{\mathrm{i}} \mathrm{C}_{\mathrm{s}}$, (f) B-type $\mathrm{C}_{\mathrm{i}} \mathrm{C}_{\mathrm{s}}$, and (g) C-type $\mathrm{C}_{\mathrm{i}} \mathrm{C}_{\mathrm{s}}$ defects with respect to the Fermi energy. Reprinted with permission from Wang et al., Sci. Rep. 4, 4909 (2014).
Figure 11 represents the optimized structures of the $\mathrm{DV}$ and $\mathrm{DVO}$ defects $(\mathrm{D}=\mathrm{Ge}, \mathrm{Sn}$, and $\mathrm{Pb})$ in the atomic chain along the (10-1) direction (refer also to Fig. 3). ${ }^{14}$ In a Si perfect crystal, the calculated nearest neighbour distance is $2.35 \AA$, which increases to $2.40 \AA$ by the vacancy in this chain in the DVO and DV defects. ${ }^{14}$ Being oversized the Sn and $\mathrm{Pb}$ dopants in a $\mathrm{D} V$ defects preferably occupy the space between two semi-vacant lattice sites in what is known as the split-vacancy configuration. ${ }^{166}$ In the $\mathrm{SnVO}$ and $\mathrm{PbVO}$ structures, the $\mathrm{O}$ interstitial atom effectively prevents $\mathrm{Sn}$ and $\mathrm{Pb}$ to shift towards the vacancy. ${ }^{14}$ This in turn is reflected upon the distance between the two $\mathrm{Si}$ atoms next to the vacancy (in the (10-1)) chain, which reduce from $3.21 \AA$ in the $V O$ structure to $2.99 \AA$ and $3.05 \AA$ in $\mathrm{Sn} V \mathrm{O}$ and $\mathrm{PbVO}$, respectively. ${ }^{14}$ The Ge-related defects are distinct as compared the $\mathrm{Sn}$ and $\mathrm{Pb}$-related defects as the size of the $\mathrm{Ge}$ atom is close to that of the $\mathrm{Si}$ atom. Consequently, the $\mathrm{GeV}$ and $\mathrm{GeVO}$ almost maintain the geometries of the structures without the Ge dopant. ${ }^{14}$

Fig. 12 reports the formation energy with respect to the Fermi energy for different charge states of the DVO and DV defects. ${ }^{14}$ Interestingly, GeVO exhibits similar behaviour to $V O$ as it transits from the charge neutral to charge -2 (at a Fermi energy of $0.47 \mathrm{eV}){ }^{14,45}$ The $\mathrm{Sn} V \mathrm{O}$ and $\mathrm{PbVO}$ defects exhibit similar behaviour as the charge neutral state is favourable in a wide Fermi energy range. Consequently, these defects are not likely to accept electrons and impact the charge carrier concentration in n-type doped $\mathrm{Si}^{14}{ }^{14}$ The $\mathrm{Ge} V$ defect has a single positive charge for low Fermi energy and a doubly negative charge for all other conditions. ${ }^{14}$ For the $\mathrm{Sn} V$ and $\mathrm{Pb} V$, the -2 charge state dominates at high Fermi energy, the +2 charge state in the low Fermi energy range (indicating that these defects can donate electrons), and there is also an intermediate region where the neutral, +1 and -1 charge states can become prevalent. $^{14}$

The $\mathrm{Ge} V$ defects are favourable to be charged and to trap charge carriers. The difference with the $\mathrm{Sn} V$ and $\mathrm{Pb} V$ defects is that for the latter states can appear in a wider energy range and this may be linked to the split-vacancy configuration resulting from the larger radii of the $\mathrm{Sn}$ and $\mathrm{Pb}$ atoms. ${ }^{14}$ The high binding energies for $\mathrm{Sn} V \mathrm{O}$ and $\mathrm{PbVO}$ illustrate that codoping with $\mathrm{Sn}$ and/or $\mathrm{Pb}$ is an efficient strategy to restrain the concentration of $V O$ defects.

In essence, the hybrid DFT studies of Wang et al. ${ }^{14}$ extended previous investigations and highlighted that oversized isovalent atoms are an effective defect engineering strategy to control the concentration of vacancy-related defects in Si. Future studies should be focused on other oversized isovalent dopants such as hafnium and zirconium for which there is limited work on $\mathrm{Si}$.

\section{SUMMARY AND FUTURE DIRECTIONS}

In the present review, we identified the issues and recent progress associated with $\mathrm{O}$ related defects in $\mathrm{Si}$ and $\mathrm{Si}_{1-\mathrm{x}} \mathrm{Ge}_{\mathrm{x}}$. Experimental studies in conjunction with DFT calculations can provide more complete understanding of the defects processes and structure of these defects. The FTIR 
(a)

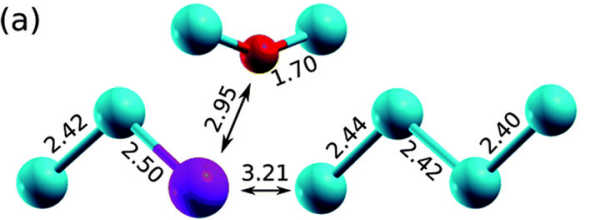

(b)

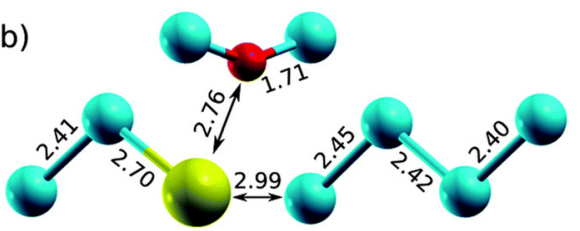

(c)

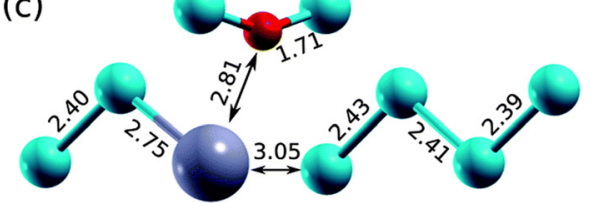

(d)

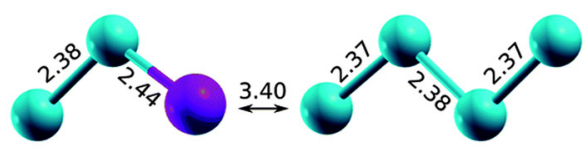

(e)

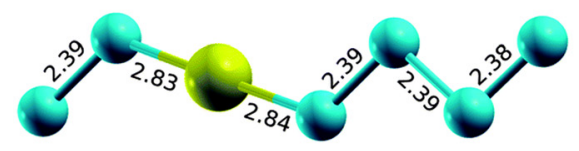

(f)

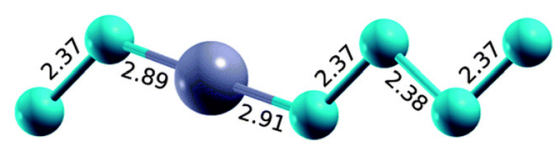

FIG. 11. Hybrid DFT calculations of the structure of the (a) $\mathrm{GeVO}$, (b) $\mathrm{SnVO}$, (c) $\mathrm{PbVO}$, (d) $\mathrm{Ge} V$, (e) $\mathrm{Sn} V$, and (f) $\mathrm{PbV}$. Only the chain along the (10-1) direction (also refer to Fig. 3 ) is shown. The big spheres represent the isovalent atoms, medium blue spheres the $\mathrm{Si}$ atoms, and small red spheres the $\mathrm{O}$ atoms. The distances are given in $\AA$. Reproduced with permission from Wang et al., Phys. Chem. Chem. Phys. 16, 8487 (2014). Copyright 2014 Royal Society of Chemistry. studies are consistent with the DFT and illustrate that large isovalent dopants, such as $\mathrm{Sn}$ or $\mathrm{Pb}$, can contain the formation of A-centers as well as their conversion to $\mathrm{VO}_{2}$ defects. DFT studies provide useful information on defects such as $\mathrm{PbV}$ which have not been observed experimentally. Additionally, they motivate the investigation of other potentially important oversized dopants such as Hf. In that respect, DFT can be utilized to design point defect engineering strategies. The present review highlights recent hybrid functional DFT results offering new evidence about the charge states of the A-center that will need to be verified by further experiments.
A fruitful and unchartered area of research will be the understanding of the impact of high concentration of $\mathrm{Sn}$ on the $\mathrm{O}$ related defects in $\mathrm{Si} \mathrm{Si}_{1-\mathrm{x}} \mathrm{Ge}_{\mathrm{x}}$. At the extreme case, the formation of A-centers in $\mathrm{Sn}_{1-\mathrm{x}} \mathrm{Ge}_{\mathrm{x}}$ alloys will provide further evidence regarding the behavior of $\mathrm{O}$ in group IV semiconductors. $\mathrm{Sn}_{1-\mathrm{x}} \mathrm{Ge}_{\mathrm{x}}$ alloys are important as they offer a range of strain options enabling the lattice matching of $\mathrm{Si}$ or $\mathrm{Si}_{1-\mathrm{x}} \mathrm{Ge}_{\mathrm{x}}$ substrates with most III-V and II-VI compounds. ${ }^{167-170}$ The properties of $\mathrm{O}$ related defects in binary and ternary group IV alloys, such as $\mathrm{Sn}_{1-\mathrm{x}} \mathrm{Ge}_{\mathrm{x}}$ and $\mathrm{Si}_{1-\mathrm{x}-\mathrm{y}} \mathrm{Ge}_{\mathrm{x}} \mathrm{Sn}_{\mathrm{y}}$, have not been investigated in detail.


FIG. 12. Hybrid DFT calculations of the formation energies as a function of the Fermi energy for different charge states of $\mathrm{D} V \mathrm{O}$ and $\mathrm{D} V$ (where $\mathrm{D}=\mathrm{Ge}$, $\mathrm{Sn}$, and $\mathrm{Pb}$ ) defects. Reproduced with permission from Wang et al., Phys. Chem. Chem. Phys. 16, 8487 (2014). Copyright 2014 Royal Society of Chemistry. 


\section{ACKNOWLEDGMENTS}

The authors acknowledge discussions over the years with Professor Robin Grimes (Imperial College London). Research reported in this publication was supported by the King Abdullah University of Science and Technology (KAUST).

${ }^{1}$ D. Tsoutsou, Y. Panayiotatos, A. Sotiropoulos, G. Mavrou, E. Golias, S. F. Galata, and A. Dimoulas, J. Appl. Phys. 108, 064115 (2010).

${ }^{2}$ D. Liu, Y. Guo, L. Lin, and J. Robertson, J. Appl. Phys. 114, 083704 (2013).

${ }^{3}$ A. R. Trivedi, T. Ando, A. Singhee, P. Kerber, E. Acar, D. J. Frank, and S. Mukhopadhyay, IEEE Trans. Electron Devices 61, 1262 (2014).

${ }^{4}$ V. V. Voronkov and R. Falster, J. Electrochem. Soc. 149, G167 (2002); V. P. Markevich, I. D. Hawkins, A. R. Peaker, K. V. Emtsev, V. V. Emtsev, V. V. Litvinov, L. I. Murin, and L. Dobaczewski, Phys. Rev. B 70, 235213 (2004); C. Claeys and E. Simoen, Germanium-Based Technologies: From Materials to Devices (Elsevier, 2007); A. Chroneos, J. Appl. Phys. 105, 056101 (2009).

${ }^{5}$ D. Yang, M. Kleverman, and L. I. Murin, Physica B 302-303, 193 (2001); M. Naganawa, Y. Smimizu, M. Uematsu, K. M. Itoh, K. Sawano, Y. Shiraki, and E. E. Haller, Appl. Phys. Lett. 93, 191905 (2008); A. Chroneos, D. Skarlatos, C. Tsamis, A. Christofi, D. S. McPhail, and R. Hung, Mater. Sci. Semicond. Process. 9, 640 (2006); R. Kube, H. Bracht, A. Chroneos, M. Posselt, and B. Schmidt, J. Appl. Phys. 106, 063534 (2009).

${ }^{6}$ V. V. Emtsev, C. A. J. Ammerlaan, V. V. Emtsev, G. A. Oganesyan, B. A. Andreev, D. I. Kuritsyn, A. Misiuk, B. Surma, and C. A. Londos, Phys. Status Solidi B 235, 75 (2003); A. Chroneos and C. A. Londos, J. Appl. Phys. 107, 093518 (2010); P. Chen, X. G. Yu, X. X. Lin, X. Z. Chen, Y. C. Wu, and D. R. Yang, Appl. Phys. Lett. 102, 082107 (2013); A. Chroneos and H. Bracht, Appl. Phys. Rev. 1, 011301 (2014).

${ }^{7}$ A. Chroneos, J. Appl. Phys. 107, 076102 (2010); A. Chroneos, C. A. Londos, and H. Bracht, Mater. Sci. Eng. B 176, 453 (2011); H. Tahini, A. Chroneos, R. W. Grimes, U. Schwingenschlögl, and A. Dimoulas, J. Phys. Condens. Matter 24, 195802 (2012).

${ }^{8}$ V. P. Markevich, I. D. Hawkins, A. R. Peaker, V. V. Litvinov, L. I. Murin, L. Dobaczewski, and J. L. Lindström, Appl. Phys. Lett. 81, 1821 (2002).

${ }^{9}$ V. P. Markevich, V. V. Litvinov, L. Dobaczewski, J. L. Lindström, L. I. Murin, S. V. Vetrov, I. D. Hawkins, and A. R. Peaker, Physica B 340-342, 844 (2003)

${ }^{10}$ H. H. Silvestri, H. Bracht, J. L. Hansen, A. N. Larsen, and E. E. Haller, Semicond. Sci. Technol. 21, 758 (2006).

${ }^{11}$ A. Chroneos and A. Dimoulas, J. Appl. Phys. 111, 023714 (2012).

${ }^{12}$ K. Kita, S. Suzuki, H. Nomura, T. Takahashi, T. Nishimura, and A. Toriumi, Jpn. J. Appl. Phys., Part 1 47, 2349 (2008).

${ }^{13}$ Y. Oshima, M. Shandalov, Y. Sun, P. Pianetta, and P. C. McIntyre, Appl. Phys. Lett. 94, 183102 (2009).

${ }^{14}$ H. Wang, A. Chroneos, C. A. Londos, E. N. Sgourou, and U. Schwingenschlogl, Phys. Chem. Chem. Phys. 16, 8487 (2014).

${ }^{15}$ A. Chroneos, C. A. Londos, and E. N. Sgourou, J. Appl. Phys. 110, 093507 (2011).

${ }^{16}$ G. D. Watkins, Mater. Sci. Semicond. Process. 3, 227 (2000).

${ }^{17}$ D. Hall, J. Gow, N. Murray, and A. Holland, IEEE Trans. Electron Devices 59, 1099 (2012)

${ }^{18}$ M. D. Segall, P. J. D. Lindan, M. J. Probert, C. J. Pickard, P. J. Hasnip, S. J. Clark, and M. C. Payne, J. Phys.: Condens. Matter 14, 2717 (2002).

${ }^{19}$ S. T. Murphy, A. Chroneos, C. Jiang, U. Schwingenschlögl, and R. W. Grimes, Phys. Rev. B 82, 073201 (2010).

${ }^{20}$ A. Chroneos, C. A. Londos, E. N. Sgourou, and P. Pochet, Appl. Phys. Lett. 99, 241901 (2011); H. Tahini, A. Chroneos, R. W. Grimes, U. Schwingenschlögl, and H. Bracht, ibid. 99, 072112 (2011); H. A. Tahini, A. Chroneos, H. Bracht, S. T. Murphy, R. W. Grimes, and U. Schwingenschlögl, ibid. 103, 142107 (2013).

${ }^{21}$ T. J. Pennycook, M. J. Beck, K. Varga, M. Varela, S. J. Pennycook, and S. T. Pantelides, Phys. Rev. Lett. 104, 115901 (2010).

${ }^{22}$ A. Kushima, D. Parfitt, A. Chroneos, B. Yildiz, J. A. Kilner, and R. W. Grimes, Phys. Chem. Chem. Phys. 13, 2242 (2011); I. D. Seymour, A. Tarancon, A. Chroneos, D. Parfitt, J. A. Kilner, and R. W. Grimes, Solid State Ionics 216, 41 (2012).
${ }^{23}$ D. Rupasov, A. Chroneos, D. Parfitt, J. A. Kilner, R. W. Grimes, S. Ya. Istomin, and E. V. Antipov, Phys. Rev. B 79, 172102 (2009); A. Chroneos, B. Yildiz, A. Tarancón, D. Parfitt, and J. A. Kilner, Energy Environ. Sci. 4, 2774 (2011).

${ }^{24}$ D. Parfitt, A. Chroneos, J. A. Kilner, and R. W. Grimes, Phys. Chem. Chem. Phys. 12, 6834 (2010); M. J. D. Rushton, A. Chroneos, S. J. Skinner, J. A. Kilner, and R. W. Grimes, Solid State Ionics 230, 37 (2013).

${ }^{25}$ S. T. Murphy, W. M. D. Cooper, and R. W. Grimes, Solid State Ionics 267, 80 (2014).

${ }^{26}$ C. A. Londos, E. N. Sgourou, D. Hall, and A. Chroneos, J. Mater. Sci.: Mater. Electron. 25, 2395 (2014).

${ }^{27}$ C. A. Londos, A. Andrianakis, E. N. Sgourou, V. V. Emtsev, and H. Ohyama, J. Appl. Phys. 109, 033508 (2011).

${ }^{28}$ C. A. Londos, D. Aliprantis, E. N. Sgourou, A. Chroneos, and P. Pochet, J. Appl. Phys. 111, 123508 (2012).

${ }^{29}$ C. A. Londos, E. N. Sgourou, and A. Chroneos, J. Appl. Phys. 112, 123517 (2012); N. V. Sarlis, C. A. Londos, and L. G. Fytros, ibid. 81, 1645 (1987)

${ }^{30}$ C. A. Londos, A. Andrianakis, V. Emtsev, and H. Ohyama, Semicond. Sci. Technol. 24, 075002 (2009).

${ }^{31}$ A. R. Bean and R. C. Newman, Solid State Commun. 9, 271 (1971).

${ }^{32}$ G. Davies and R. C. Newman, in Handbook of Semiconductors, edited by S. Mahajan (Elsevier, Amsterdam, 1994), Vol. 3, pp. 1557-1635; N. Inoue, A. Ohyama, Y. Goto, and T. Sugiyama, Physica B 401-402, 477 (2007).

${ }^{33}$ E. V. Lavrov, L. Hoffmann, and B. Nielsen, Phys. Rev. B 60, 8081 (1999).

${ }^{34}$ C. A. Londos, M. S. Potsidi, and E. Stakakis, Physica B 340-342, 551 (2003).

${ }^{35}$ C. A. Londos, M. S. Potsidi, G. D. Antonaras, and A. Andrianakis, Physica B 376-377, 165 (2006).

${ }^{36}$ L. I. Murin, J. L. Lindstrom, G. Davies, and V. P. Markevich, Nucl. Instrum. Methods Phys. Res., Sect. B 253, 210 (2006).

${ }^{37}$ D. J. Backlund and S. K. Estreicher, Physica B 401-402, 163 (2007).

${ }^{38}$ D. J. Backlund and S. K. Estreicher, Phys. Rev. B 77, 205205 (2008).

${ }^{39}$ C. A. Londos, E. N. Sgourou, D. Timerkaeva, A. Chroneos, P. Pochet, and V. V. Emtsev, J. Appl. Phys. 114, 113504 (2013).

${ }^{40} \mathrm{~B}$. Pajot and B. Clerjaud, in Optical Absorption of Impurities and Defects in Semiconducting Crystals, II. Electronic Absorption of Deep Centers and Vibrational Spectra, Springer Series in Solid-state physics Vol. 169 (Springer-Verlag, Berlin Heidelberg, 2013).

${ }^{41}$ D. R. Bosomworth, W. Hayes, A. R. L. Spray, and G. D. Watkins, Proc. R. Soc. London, Ser. A 317, 133 (1970).

${ }^{42}$ T. Halberg, L. I. Murin, J. L. Lindström, and V. P. Markevich, J. Appl. Phys. 84, 2466 (1998).

${ }^{43}$ H. Yamada-Kaneta, Phys. Status Solidi C 0, 673 (2003).

${ }^{44}$ C. A. Londos, Phys. Stat. Solidi (a) 113, 503 (1989); G. D. Watkins and J. W. Corbett, Phys. Rev. 121, 1001 (1961).

${ }^{45} \mathrm{H}$. Wang, A. Chroneos, C. A. Londos, E. N. Sgourou, and U. Schwingenschlogl, Appl. Phys. Lett. 103, 052101 (2013).

${ }^{46}$ B. Pajot, Semiconductors and Semimetals, Oxygen in Silicon Vol. 42, edited by F. Shimura (Academic, London, 1994), p. 191.

${ }^{47}$ J. Coutinho, R. Jones, P. R. Briddon, and S. Öberg, Phys. Rev. B 62, 10824 (2000).

${ }^{48}$ J. L. Lindstrom, L. I. Murin, V. P. Markevich, T. Hallberg, and B. G. Svensson, Physica B 273-274, 291 (1999).

${ }^{49}$ T. Umeda, Y. Mochizuchi, K. Okonogi, and K. Hamada, Physica B 308-310, 1169 (2001).

${ }^{50}$ T. Umeda, K. Ohyu, S. Tsukada, K. Hamada, S. Fujieda, and Y. Mochizuchi, Appl. Phys. Lett. 88, 253504 (2006).

${ }^{51}$ K. Gill, G. Hall, and B. MacEvoy, J. Appl. Phys. 82, 126 (1997).

${ }^{52}$ A. Hallen, N. Keskitalo, F. Masszi, and V. Nagl, J. Appl. Phys. 79, 3906 (1996).

${ }^{53}$ I. Murin, J. L. Lindstrom, V. P. Markevich, A. Misiuk, and C. A. Londos, J. Phys.: Condens. Matter 17, S2237 (2005).

${ }^{54}$ T. Hallberg and J. L. Lindstrom, J. Appl. Phys. 72, 5130 (1992).

${ }^{55}$ V. Akhmetov, G. Kissinger, and W. von Ammon, Physica B 404, 4572 (2009).

${ }^{56}$ B. Surma, C. A. Londos, V. V. Emtsev, A. Misiuk, A. Bukowski, and M. S. Potsidi, Mater. Sci. Eng. B 102, 339 (2003).

${ }^{57}$ B. O. Kolbersen and A. Mühlbauer, Solid State Electron. 25, 759 (1982).

${ }^{58}$ R. C. Newman, MRS Proc. 59, 403 (1985).

${ }^{59}$ R. C. Newman and R. Jones, "Oxygen in silicon," in Semiconductors and Semimetals, edited by F. Shimura (Academic Press, Orlando, 1994), Vol. 42 , p. 289 
${ }^{60}$ W. Scorupa and R. A. Yankov, Mater. Chem. Phys. 44, 101 (1996).

${ }^{61}$ R. C. Newman and A. R. Bean, Radiat. Eff. 8, 189 (1971).

${ }^{62}$ G. D. Watkins and K. L. Brower, Phys. Rev. Lett. 36, 1329 (1976).

${ }^{63}$ F. L. Vook and H. J. Stein, Appl. Phys. Lett. 13, 343 (1968).

${ }^{64}$ C. A. Londos, Phys. Rev. B 35, 6295 (1987).

${ }^{65}$ G. Davies, E. C. Lightowlers, R. C. Newman, and A. S. Oates, Semicond. Sci. Technol. 2, 524 (1987).

${ }^{66}$ C. L. Liu, W. Windl, L. Borucki, S. Lu, and X. Y. Liu, Appl. Phys. Lett. 80, 52 (2002).

${ }^{67}$ H. Wang, A. Chroneos, C. A. Londos, E. N. Sgourou, and U. Schwingenschlögl, Sci. Rep. 4, 4909 (2014).

${ }^{68}$ S. D. Brotherton and P. Bradley, J. Appl. Phys. 53, 5720 (1982).

${ }^{69}$ J. M. Trombetta and G. D. Watkins, Appl. Phys. Lett. 51, 1103 (1987).

${ }^{70}$ J. Coutinho, R. Jones, P. R. Briddon, S. Öberg, L. I. Murin, V. P. Markevich, and J. L. Lindström, Phys. Rev. B 65, 014109 (2001).

${ }^{71}$ S. G. Cloutier, P. A. Kossyrev, and J. Xu, Nat. Mater. 4, 887 (2005).

${ }^{72}$ E. Rotem, J. M. Shainline, and J. M. Xu, Appl. Phys. Lett. 91, 051127 (2007).

${ }^{73}$ K. Murata, Y. Yasutake, K. Nittoh, S. Fukatsu, and K. Miki, AIP Adv. 1 , 032125 (2011).

${ }^{74}$ D. D. Berhanuddin, M. A. Lourenço, R. M. Gwilliam, and K. P. Homewood, Adv. Funct. Mater. 22, 2709 (2012).

${ }^{75}$ A. Mattoni, F. Bernantini, and L. Colombo, Phys. Rev. B 66, 195214 (2002).

${ }^{76}$ M. S. Potsidi and C. A. Londos, J. Appl. Phys. 100, 033523 (2006).

${ }^{77}$ S. M. Hu, Appl. Phys. Lett. 31, 53 (1977).

${ }^{78}$ D. Gilles, E. R. Weber, and S. Hahn, Phys. Rev. Lett. 64, 196 (1990).

${ }^{79} \mathrm{~K}$. Sumino and I. Yonenaga, in Semiconductors and Semimetals, edited by F. Shimura (Academic, New York, 1994), Vol. 42, p. 449.

${ }^{80}$ S. Senkader, K. Jurkschat, D. Gambaro, R. J. Falster, and P. R. Wilshaw, Philos. Mag. A 81, 759 (2001).

${ }^{81}$ J. D. Murphy, P. R. Wilshaw, B. C. Pygall, S. Senkader, and R. J. Falster, J. Appl. Phys. 100, 103531 (2006).

${ }^{82}$ H. Helmreich and E. Sirtl, Semiconductor Silicon, edited by H. R. Huff and E. Sirtl (ECS, 1981), p. 626.

${ }^{83}$ U. Gösele and T. Tan, Appl. Phys. A 28, 79 (1982).

${ }^{84}$ U. Gösele, K. Y. Ahn, B. Marioton, T. Tan, and S. T. Lee, Appl. Phys. A 48, 219 (1989).

${ }^{85}$ Y. J. lee, J. von Boem, M. Pesola, and R. M. Nieminen, Phys. Rev. B 65, 085205 (2002)

${ }^{86}$ H. Takena, Y. Hayamizu, and K. Miki, J. Appl. Phys. 84, 3113 (1998).

${ }^{87}$ C. Chui, X. Ma, and D. Yang, Phys. Status Solidi A 205, 1148 (2008).

${ }^{88}$ D. Timerkaeva, D. Caliste, and P. Pochet, Appl. Phys. Lett. 103, 251909 (2013).

${ }^{89}$ J. Adey, R. Jones, D. W. Palmer, P. R. Briddon, and S. Öberg, Phys. Rev. Lett. 93, 055504 (2004).

${ }^{90}$ A. S. Oates and R. C. Newman, Appl. Phys. Lett. 49, 262 (1986).

${ }^{91}$ R. C. Newman, J. Phys.: Condens. Matter 12, R335 (2000).

${ }^{92}$ T. Sinno, J. Dai, and S. S. Kapur, Mater. Sci. Eng. B 159-160, 128 (2009).

${ }^{93}$ R. Falster and V. V. Voronkov, Mater. Sci. Eng. B 73, 87 (2000).

${ }^{94}$ H. Bracht, S. Schneider, J. N. Klug, C. Y. Liao, J. L. Hansen, E. E. Haller, A. N. Larsen, D. Bougeard, M. Posselt, and C. Wündisch, Phys. Rev. Lett. 103, 255501 (2009).

${ }^{95}$ S. Brotzmann and H. Bracht, J. Appl. Phys. 103, 033508 (2008).

${ }^{96} \mathrm{~A}$. Chroneos, H. Bracht, R. W. Grimes, and B. P. Uberuaga, Appl. Phys. Lett. 92, 172103 (2008).

${ }^{97}$ P. Tsouroutas, D. Tsoukalas, and H. Bracht, J. Appl. Phys. 108, 024903 (2010).

${ }^{98}$ S. Brotzmann, H. Bracht, J. L. Hansen, A. N. Larsen, E. Simoen, E. E. Haller, J. S. Christensen, and P. Werner, Phys. Rev. B 77, 235207 (2008).

${ }^{99}$ A. Chroneos, R. W. Grimes, B. P. Uberuaga, and H. Bracht, Phys. Rev. B 77, 235208 (2008)

${ }^{100}$ M. Diebel and S. T. Dunham, Phys. Rev. Lett. 93, 245901 (2004).

${ }^{101}$ F. Bernardi, J. H. R. dos Santos, and M. Behar, Phys. Rev. B 76, 033201 (2007)

${ }^{102}$ S. Boninelli, G. Impellizzeri, S. Mirabella, F. Priolo, E. Napolitani, N. Cherkashin, and F. Cristiano, Appl. Phys. Lett. 93, 061906 (2008).

${ }^{103}$ A. Chroneos, R. W. Grimes, and H. Bracht, J. Appl. Phys. 106, 063707 (2009).

${ }^{104}$ G. Impellizzeri, S. Boninelli, F. Priolo, E. Napolitani, C. Spinella, A. Chroneos, and H. Bracht, J. Appl. Phys. 109, 113527 (2011).

${ }^{105}$ W. S. Jung, J. H. Park, A. Nainani, D. Nam, and K. C. Saraswat, Appl. Phys. Lett. 101, 072104 (2012).
${ }^{106}$ K. Weiser, J. Phys. Chem. Solids 7, 118 (1958).

${ }^{107}$ A. Brelot and J. Charlemagne, Radiat. Eff. 9, 65 (1971).

${ }^{108}$ M. L. David, E. Simoen, C. Clays, V. B. Neimash, N. Kra'sko, A. Kraitchinscii, V. Voytovych, V. Tishchenko, and J. F. Barbot, in Proceedings of High Purity Silicon VIII (The Electrochemical Society, 2004), Vol. 2004-05, p. 395.

${ }^{109}$ V. G. Golubev, V. V. Emtsev, P. M. Klinger, G. I. Kropotov, and Yu. V Shmartsev, Sov. Phys. Semicond. 26, 328 (1992).

${ }^{110}$ N. A. Sobolev and M. H. Nazarre, Physica B 273-274, 271 (1999).

${ }^{111}$ Yu. V. Pomozov, L. I. Khirunenko, V. I. Shakhovtsov, and V. I. Yashnik, Sov. Phys. Semicond. 24, 624 (1990)

${ }^{112}$ V. V. Voronkov, R. Falster, C. A. Londos, E. N. Sgourou, A. Andrianakis, and H. Ohyama, J. Appl. Phys. 110, 093510 (2011).

${ }^{113}$ C. Cui, D. Yang, X. Ma, M. Li, and D. Que, Mater. Sci. Semicond. Process. 9, 110 (2006)

${ }^{114}$ D. Yang, Phys. Status Solidi A 202, 931 (2005).

${ }^{115}$ X. Yu, J. Chen, X. Ma, and D. Yang, Mater. Sci. Eng. R 74, 1 (2013).

${ }^{116}$ J. Chen, D. Yang, X. Ma, Z. Zeng, D. Tian, L. Li, D. Que, and L. Gong, J. Appl. Phys. 103, 123521 (2008).

${ }^{117}$ M. Arivanandhan, R. Gotoh, K. Fujiwara, and S. Uda, Appl. Phys. Lett. 94, 072102 (2009).

${ }^{118}$ L. Wang, P. Clancy, and C. S. Murthy, Phys. Rev. B 70, 165206 (2004).

${ }^{119}$ O. V. Aleksandrov and N. N. Afonin, Semicond. Sci. Technol. 18, 139 (2003).

${ }^{120}$ Z. Zeng, J. D. Murphy, R. J. Falster, X. Ma, D. Yang, and D. Wilshaw, J. Appl. Phys. 109, 063532 (2011).

${ }^{121}$ X. Zhu, X. Yu, and D. Yang, J. Cryst. Growth 401, 141 (2014).

${ }^{122}$ M. Arivanandhan, R. Gotoh, T. Watahiki, K. Fujiwara, Y. Hayakawa, S. Uda, and M. Konagai, J. Appl. Phys. 111, 043707 (2012).

${ }^{123}$ P. Wang, X. Yu, P. Chen, X. Li, D. Yang, X. Chen, and Z. Haung, Sol. Energy Mater. Sol. Cells 95, 2466 (2011).

${ }^{124}$ F. Tanay, S. Dubois, N. Enjalbert, J. Veirman, P. Gidon, and I. Perichaud, Phys. Status Solidi C 9, 1981 (2012).

${ }^{125}$ X. Yu, P. Wang, P. Chen, X. Li, and D. Yang, Appl. Phys. Lett. 97, 051903 (2010).

${ }^{126}$ G. D. Watkins, Phys. Rev. B 12, 4383 (1975)

${ }^{127}$ V. B. Neimash, M. G. Sosnin, B. M. Turovskii, V. P. Markevich, V. I. Shakhovtsov, and V. L. Shindich, Sov. Phys. Semicond. 16, 577 (1982).

${ }^{128}$ L. I. Khirunenko, O. A. Kobzar, Yu. V. Pomozov, V. I. Shakhovstov, M. G. Sosnin, N. A. Tripachko, V. P. Markevich, L. I. Murin, and A. R. Peaker, Phys. Status Solidi C 0, 694 (2003).

${ }^{129}$ E. Simoen, C. Clays, V. Neimash, A. Kraitchinskii, N. Kras'ko, O. Puzenko, A. Blondeel, and P. Clauws, Appl. Phys. Lett. 76, 2838 (2000).

${ }^{130}$ A. N. Larsen, J. J. Goubet, P. Mejlholm, J. S. Christensen, M. Fanciulli, H. P. Gunnlaugsson, P. Weyer, J. W. Petersen, A. Resende, M. Kaukonen, R. Jones, S. Oberg, P. R. Briddon, B. G. Svensson, and S. Dannefaer, Phys. Rev. B 62, 4535 (2000).

${ }^{131}$ E. V. Lavrov, M. Fancialli, M. Kaukonen, R. Jones, and P. R. Briddon, Phys. Rev. B 64, 125212 (2001).

${ }^{132}$ L. I. Khirunenko, O. A. Kobzar, Yu V. Pomozov, M. G. Sosnin, N. A. Tripachko, N. V. Abrosimov, and H. Riemann, Solid State Phenom. 95-96, 393 (2004).

${ }^{133}$ M. L. David, E. Simoen, C. Clays, V. Neimash, N. Kras'ko, A. Kraitchinskii, V. Voytovych, A. Kabaldin, and J. F. Barbot, J. Phys.: Condens. Matter 17, S2255 (2005).

${ }^{134}$ J. Fage-Pedersen, A. N. Larsen, P. Gaiduk, and J. L. Hansen, Phys. Rev. Lett. 81, 5856 (1998).

${ }^{135}$ A. Brelot, IEEE Trans. Nucl. Sci. 19, 220 (1972).

${ }^{136}$ T. H. Yeh and M. L. Joshi, J. Electrochem. Soc. 116, 73 (1969).

${ }^{137}$ K. Yagi, N. Miyamoto, and J.-I. Nishizawa, Jpn. J. Appl. Phys., Part 19 , 246 (1970).

${ }^{138}$ M. Fanciulli and J. R. Byberg, Physica B 273-274, 524 (1999).

${ }^{139}$ C. Claeys, E. Simoen, V. B. Neimash, A. Kraitchinskii, M. Kras'ko, O. Puzenko, A. Blondeel, and P. Clauws, J. Electrochem. Soc. 148, G738 (2001).

${ }^{140}$ E. Simoen, C. Clays, V. Privitera, S. Coffa, A. N. Larsen, and P. Clauws, Physica B 308-310, 477 (2001).

${ }^{141}$ W. Wijaranakula, J. Appl. Phys. 72, 2713 (1992).

${ }^{142}$ V. B. Neimash, A. Kraitchinskii, M. Kras'ko, O. Puzenko, C. Claeys, E. Simoen, B. Svensson, and A. Kuznetsov, J. Electrochem. Soc. 147, 2727 (2000).

${ }^{143}$ C. Ghao, X. Ma, J. Zhao, and D. Yang, J. Appl. Phys. 113, 093511 (2013).

${ }^{144}$ D. E. Hill, H. W. Gutsche, M. S. Wang, K. P. Gupta, W. F. Tucker, J. D. Dowdy, and R. J. Crepin, in 12th IEEE Phtovoltaic Specialists 
Conference, Baton Rouge, La., November 15-18, 1976, Conference Record (A78-10902 01-44), New York, 1976, pp. 112-119.

${ }^{145}$ Y. V. Pomozov, M. G. Sosnin, L. I. Khirunenko, V. I. Yashnik, N. V. Abrosimov, W. Schröder, and M. Höhne, Semiconductors 34, 989 (2000).

${ }^{146}$ V. P. Markevich, A. R. Peaker, L. I. Murin, and N. V. Abrosimov, Appl. Phys. Lett. 82, 2652 (2003).

${ }^{147}$ V. P. Markevich, A. R. Peaker, J. Coutinho, R. Jones, V. J. B. Torres, S. Öberg, P. R. Briddon, L. I. Murin, L. Dobaczewski, and N. V. Abrosimov, Phys. Rev. B 69, 125218 (2004).

${ }^{148}$ I. Yonenaga, M. Nonaka, and N. Fukata, Physica B 308-310, 539 (2001).

${ }^{149}$ S. Hao, L. Kantorovich, and G. Davies, Phys. Rev. B 69, 155204 (2004).

${ }^{150}$ S. L. Sihto, J. Slotte, J. Lento, K. Saarinen, E. V. Monakhov, A. Yu. Kuznetsov, and B. G. Svensson, Phys. Rev. B 68, 115307 (2003).

${ }^{151}$ A. Chroneos, H. Bracht, C. Jiang, B. P. Uberuaga, and R. W. Grimes, Phys. Rev. B 78, 195201 (2008).

${ }^{152}$ J. Chen, D. Yang, X. Ma, R. Fan, and D. Que, J. Appl. Phys. 102, 066102 (2007).

${ }^{153}$ C. A. Londos, A. Andrianakis, V. Emtsev, and H. Ohyama, J. Appl. Phys. 105, 123508 (2009).

${ }^{154}$ E. N. Sgourou, A. Andrianakis, C. A. Londos, and A. Chroneos, J. Appl. Phys. 113, 113507 (2013).

${ }^{155}$ L. I. Khirunenko, V. I. Shakhovtsov, and V. V. Shumov, Semiconductors 32, 120 (1998).

${ }^{156}$ C. A. Londos, A. Andrianakis, V. V. Emtsev, G. A. Oganesyan, and H. Ohyama, Mater. Sci. Eng. B 154-155, 133 (2008).
${ }^{157}$ J. Heyd, G. E. Scuseria, and M. Ernzerhof, J. Chem. Phys. 118, 8207 (2003).

${ }^{158}$ J. Heyd, G. E. Scuseria, and M. Ernzerhof, J. Chem. Phys. 124, 219906 (2006).

${ }^{159}$ M. Pesola, J. Von Boehm, T. Mattila, and R. M. Nieminen, Phys. Rev. B 60, 11449 (1999).

${ }^{160}$ V. V. Voronkov and R. Falster, Mater. Sci. Eng. B 134, 227 (2006).

${ }^{161}$ H. Bracht and A. Chroneos, J. Appl. Phys. 104, 076108 (2008).

${ }^{162}$ R. Jones and S. Öberg, Phys. Rev. Lett. 68, 86 (1992).

${ }^{163}$ L. W. Song, X. D. Zhan, B. W. Benson, and G. D. Watkins, Phys. Rev. B 42, 5765 (1990).

${ }^{164}$ E. N. Sgourou, D. Timerkaeva, C. A. Londos, D. Aliprantis, A. Chroneos, D. Caliste, and P. Pochet, J. Appl. Phys. 113, 113506 (2013).

${ }^{165}$ F. Zirkelbach, B. Stritzker, K. Nordlund, J. K. N. Lindner, W. G. Schmidt, and E. Rauls, Phys. Rev. B 84, 064126 (2011).

${ }^{166}$ H. Höhler, N. Atodiresei, K. Schroeder, R. Zeller, and P. Dederichs, Phys. Rev. B 71, 35212 (2005).

${ }^{167}$ A. V. G. Chizmeshya, M. R. Bauer, and J. Kouvetakis, Chem. Mater. 15, 2511 (2003).

${ }^{168}$ R. Roucka, J. Tolle, C. Cook, A. V. G. Chizmeshya, J. Kouvetakis, V. D'Costa, J. Menendez, and Z. D. Chen, Appl. Phys. Lett. 86, 191912 (2005).

${ }^{169}$ J. Kouvetakis, J. Menendez, and A. V. G. Chizmeshya, Ann. Rev. Mater. Res. 36, 497 (2006); A. Chroneos, H. Bracht, R. W. Grimes, and B. P. Uberuaga, Mater. Sci. Eng. B 154-155, 72 (2008).

${ }^{170}$ A. Chroneos, C. Jiang, R. W. Grimes, U. Schwingenschlögl, and H. Bracht, Appl. Phys. Lett. 94, 252104 (2009); 95, 112101 (2009). 